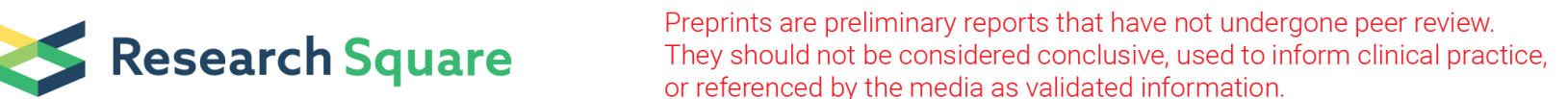

\section{Surface And Aloft $\mathrm{NO}_{2}$ Pollution Over The Greater Tokyo Area Observed By Ground-Based And MAX- DOAS Measurements Bridged By Regional Air Quality Modeling}

Syuichi Itahashi ( $\square$ isyuichi@criepi.denken.or.jp)

Central Research Institute of Electric Power Industry: Denryoku Chuo Kenkyujo https://orcid.org/00000001-7567-7831

Hitoshi Irie

Chiba University: Chiba Daigaku

\section{Research article}

Keywords: Nitrogen dioxide, AEROS, MAX-DOAS, Air quality model, high-resolution modeling, planetary boundary layer, Chiba-Campaign 2015

Posted Date: July 15th, 2021

DOI: https://doi.org/10.21203/rs.3.rs-708775/v1

License: (9) This work is licensed under a Creative Commons Attribution 4.0 International License. Read Full License 


\section{Abstract}

To advance our understanding of surface and aloft nitrogen dioxide $\left(\mathrm{NO}_{2}\right)$ pollution, this study extensively evaluated $\mathrm{NO}_{2}$ concentrations simulated by the regional air quality modeling system with a horizontal grid resolution of $1.3 \mathrm{~km}$ by using the Atmospheric Environmental Regional Observation System (AEROS) ground-based observation network and aloft measurement by multi-axis differential optical absorption spectroscopy (MAX-DOAS) over the greater Tokyo area. Observations are usually limited to the surface level, and gaps remain in our understanding of the behavior of air pollutants above the near-surface layer, particularly within the planetary boundary layer (PBL). Therefore, MAX-DOAS measurement was used, which observes scattered sunlight in the ultraviolet/visible range at several elevation angles between the horizon and zenith to determine the aloft $\mathrm{NO}_{2}$ pollution averaged over $0-1$ $\mathrm{km}$. In total, four MAX-DOAS measurement systems at Chiba University $\left(35.63^{\circ} \mathrm{N}, 140.10^{\circ} \mathrm{E}\right)$ systematically covered the north, east, west, and south directions to capture the aloft $\mathrm{NO}_{2}$ pollution over the greater Tokyo area. The target period was Chiba-Campaign 2015 conducted from 9 to 23 November 2015. The evaluations showed that the air quality modeling system can generally capture the observed behavior of both surface and aloft $\mathrm{NO}_{2}$ pollution in terms of spatial and temporal coverage. The diurnal variation, which typically showed an increase from evening to early morning without daylight and a decrease during the daytime, was also captured by the model. During Chiba-Campaign 2015, two cases of episodic higher $\mathrm{NO}_{2}$ concentration were identified: one during the nighttime and the other during the daytime as different diurnal patterns. These were related to a stagnant wind field, with the latter also connected to a lower PBL height in cloudy conditions. Comparison of the modeled surface and aloft $\mathrm{NO}_{2}$ concentrations showed that aloft $\mathrm{NO}_{2}$ concentration exhibited a strong linear correlation with surface $\mathrm{NO}_{2}$ concentration, with the aloft value scaled to $0.4-0.5$-fold the surface value, irrespective of whether the day was clean or polluted. This scaling value was lower during the nighttime and higher during the daytime. Based on this synergetic analysis of surface and aloft observation bridged by modeling simulation, this study contributes to fostering understanding of aloft $\mathrm{NO}_{2}$ pollution.

\section{Introduction}

Nitrogen oxides $\left(\mathrm{NO}_{\mathrm{x}}\right)$, which collectively refers to nitric oxide $(\mathrm{NO})$ and nitrogen dioxide $\left(\mathrm{NO}_{2}\right)$, play a crucial role in tropospheric chemistry and have important implications for air quality and climate (Seinfeld and Pandis 2016). $\mathrm{NO}_{\mathrm{x}}$ is mainly emitted into the atmosphere as NO from anthropogenic sources (e.g., fossil fuel combustion) and natural sources (e.g., microbiological processes in soil and lightning) (Lin 2012; Kurokawa et al. 2013). Since $\mathrm{NO}_{2}$ can affect human respiratory organs at high concentrations, an air quality standard (AQS) was established for $\mathrm{NO}_{2}$ in 1973 and revised in 1978 in Japan. To satisfy this AQS, the daily average of hourly values of $\mathrm{NO}_{2}$ concentrations must be $0.04-0.06$ ppm or lower. In Japan, the AQS for $\mathrm{NO}_{2}$ is mostly satisfied except at a few sites located close to roadsides (Wakamatsu et al. 2013). Given that the placement of ground-based observation is generally designed to protect human health, and most of observation sites are located in densely populated areas, 
observation sites are sparse in rural and remote areas. To obtain a homogeneous spatial distribution of air pollutants, satellite observation can serve as a useful tool and our previous studies have reported space-borne $\mathrm{NO}_{2}$ pollution over Asia and Japan (Irie et al. 2016; Itahashi et al. 2014; Itahashi et al. 2019; Choi et al. 2021). Although satellite observations have the potential to contribute to understanding spatial distribution patterns, the observed concentration is the amount vertically integrated over the column from the surface through the entire troposphere or sliced layers within the troposphere. To focus on the nearsurface $\mathrm{NO}_{2}$ behavior, additional observations are desired. This study fully utilizes multi-axis differential optical absorption spectroscopy (MAX-DOAS). MAX-DOAS is able to measure vertical profiles by observing scattered sunlight in the ultraviolet (UV)/visible range at several elevation angles between the horizon and zenith. By combining ground-based observation with MAX-DOAS, surface and aloft $\mathrm{NO}_{2}$ pollution can be monitored. However, nighttime aloft $\mathrm{NO}_{2}$ cannot be detected because the principles of operation of MAX-DOAS relies on sunlight. To bridge spatial and temporal information, further regional air quality modeling needs to be conducted. This study therefore aims to understand the behavior of surface and aloft $\mathrm{NO}_{2}$ and to fill in gaps in our understanding of the status of $\mathrm{NO}_{2}$ pollution within the planetary boundary layer (PBL).

\section{Methods}

Chiba prefecture is located to the east of Tokyo and is part of the greater Tokyo area (Tokyo, Kanagawa, Saitama, and Chiba). At Chiba University, located in the central part of Chiba prefecture, an intensive observation campaign (Chiba-Campaign 2015) was conducted from 9 to 22 November 2015. This campaign is the target of this study, through which we aim to understand the behavior of surface and aloft $\mathrm{NO}_{2}$ and to fill in gaps in our understanding of the status of $\mathrm{NO}_{2}$ pollution within the PBL. Section 2.1 presents the ground-based observation. Section 2.2 describes the MAX-DOAS measurement. Section 2.3 introduces the regional air quality modeling.

\subsection{Ground-based observation}

Ground-based observation of air pollutants that are regulated by AQS (carbon monoxide (CO), sulfur dioxide $\left(\mathrm{SO}_{2}\right), \mathrm{NO}_{2}$, photochemical oxidants $\left(\mathrm{O}_{\mathrm{x}}\right)$, suspended particulate matter (SPM), and particulate matter with aerodynamic diameter less than to $\left.2.5 \mu \mathrm{m}\left(\mathrm{PM}_{2.5}\right)\right)$ have been routinely measured by the Atmospheric Environmental Regional Observation System (AEROS) (http://soramame.taiki.go.jp). AEROS has two goals: to monitor ambient air quality using ambient air pollution monitoring stations (APMSs) and to measure air pollution particularly due to transportation such as automobiles using roadside air pollution monitoring stations (RAPMSs). The locations of AEROS over Chiba prefecture are shown in Fig. 1a. During the analyzed period of Chiba-Campaign 2015, surface $\mathrm{NO}_{2}$ concentration was monitored at a total of 100 APMS sites and 27 RAPMS sites. Among these AEROS sites, sites located within $24 \mathrm{~km}$ (the maximum horizontal distance measured by MAX-DOAS, see Sect. 2.2) of Chiba University were used for the analysis.

\subsection{MAX-DOAS observation}


Aloft observations using MAX-DOAS systems (Irie et al., 2008, 2011, 2015, 2019, 2021) have been conducted at Chiba University $\left(35.63^{\circ} \mathrm{N}, 140.10^{\circ} \mathrm{E}, 21 \mathrm{~m}\right.$ a.s.I.), Chiba, Japan. The MAX-DOAS methodology is based on the differential optical absorption spectroscopy (DOAS) method, which quantitatively detects narrow-band absorption by trace gases by applying the Beer-Lambert law (Platt and Stutz 2008). Following on from the pioneering studies of Hönninger and Platt (2002) and Hönninger et al. (2004), various instruments and algorithms have been developed worldwide for MAX-DOAS. The MAXDOAS system at Chiba University has participated in the Cabauw Intercomparison Campaign of Nitrogen Dioxide measuring Instruments (CINDI) (Roscoe et al. 2010) and CINDI-2 (Kreher et al. 2020). The MAXDOAS system in this study uses the Maya2000Pro spectrometer (Ocean Optics, Inc.) with a $25 \mu \mathrm{m}$ slit which was placed in a temperature-controlled enclosure in order to record high-resolution spectra (full width at half maximum: ca. 0.3-0.4 nm; oversampling: 3-4) in the wavelength range 310 to $515 \mathrm{~nm}$. Measurement was performed at 5 off-axis elevation angles (e.g., $2^{\circ}, 3^{\circ}, 4^{\circ}, 6^{\circ}, 8^{\circ}$ ) and at a single reference elevation angle, with $70^{\circ}$ used instead of $90^{\circ}$ to reduce the range of variation in signals measured at all elevation angles while keeping the integration time constant. Although the original observation by MAXDOAS targets a single direction, four different azimuth-viewing MAX-DOAS (4AZ-MAX-DOAS) instruments are used at Chiba University to cover the cardinal compass point simultaneously: north $\left(13^{\circ} \mathrm{W}\right)$, west $\left(95^{\circ} \mathrm{W}\right)$, east $\left(118^{\circ} \mathrm{E}\right)$, and south $\left(175^{\circ} \mathrm{E}\right)$. The location of Chiba University and the directions covered by the 4AZ-MAX-DOAS are shown in Fig. 1b. To derive near-surface concentrations, we used our retrieval algorithm called JM2 (Japanese MAX-DOAS profile retrieval algorithm, version 2) (Irie et al. 2008; Irie et al. 2011; Irie et al. 2015). JM2 uses the recorded high-resolution UV-visible spectra from 310 to $515 \mathrm{~nm}$ to perform spectral analysis by the DOAS method (Platt and Stutz 2008) by spectral fitting using the nonlinear least-squares method and subsequent vertical profile retrievals using the optimal estimation method, which allows us to retrieve lower-tropospheric vertical profile information for 8 quantities including $\mathrm{NO}_{2}$. The adopted fitting windows and cross section data are identical to those described by Irie et al. $(2011,2015)$. In the retrieval, off-axis elevation angles are limited to below $10^{\circ}$ in order to minimize the possible systematic error in oxygen collision complex fitting results (Irie et al. 2015). This enhances the ability to observe the PBL thanks to the loss of sensitivity to extinction at high altitudes, where clouds rather than aerosols predominate. Thus, our MAX-DOAS system has been optimized to retrieve information on aerosols and trace gases in the PBL rather than in the whole tropospheric column. For the vertical profile retrieval, full consideration is given to the elevation angle setting when computing differential air mass factors (Irie et al. 2011, 2015). There are usually about 1-2 degrees of freedom of signals for trace gas vertical profiles retrieved in this way. With the retrieved vertical profiles, the present study analyzed the layer at 0-1 km, which corresponds to the lowermost layer with the highest sensitivity owing to the longest light path in profiles retrieved by JM2. In the horizontal direction, the viewed horizontal distance in each direction is up to $24 \mathrm{~km}$. In Fig. 1b, horizontal scales up to $24 \mathrm{~km}$ from Chiba University are shown at $4 \mathrm{~km}$ intervals as a visual guide. The total uncertainties, including random and systematic errors, in a single measurement were estimated as $15 \%$ for $\mathrm{NO}_{2}$ (Irie et al. 2011), and the estimated systematic error was based on additional retrievals of JM2 aerosol retrieval uncertainties of as large as 30\% (Irie et al. 2008; Irie et al. 2011). The estimated relative humidity over water $\left(\mathrm{RH}_{\mathrm{w}}\right)$ for the $0-$ $1 \mathrm{~km}$ layer was based on the retrieved $\mathrm{H}_{2} \mathrm{O}$ concentration from the National Centers for Environmental 
Prediction (NCEP) pressure and temperature reanalysis data (2.5 grid and 6-hourly). For cloud screening, we analyzed only data with $\mathrm{RH}_{\mathrm{w}}$ lower than $90 \%$.

\subsection{Regional air quality modeling}

The regional air quality modeling was based on Community Multiscale Air Quality (CMAQ) version 5.2.1 released by the US Environmental Protection Agency (US EPA 2018). The simulation used quadruple nesting covering all of Asia, Japan, the extended Kanto region, and Chiba prefecture with horizontal grid resolutions of $36,12,4$, and $1.3 \mathrm{~km}$ (Fig. 2). For comparison with observations, the domain with the finest resolution of $1.3 \mathrm{~km}$ was used. In the vertical direction, 44 nonuniform layers from the surface to $50 \mathrm{hPa}$ were set to fully represent the stratosphere-to-troposphere transport (Mathur et al. 2017; Itahashi et al. 2020). The height of the lowermost layer which corresponded to modeling surface level was approximately $20 \mathrm{~m}$. The meteorological input data were simulated by the Weather Research and Forecasting (WRF) model version 3.6.1 (Skamarock et al. 2008) to drive the CMAQ. The configuration of the WRF simulation is basically the same as our previous study (Itahashi 2018). For both longwave and shortwave radiation, the rapid radiative transfer model for global climate models (RRTMG) radiation scheme was used (lacono et al. 2008), and the Morrison double-moment scheme (Morrison et al. 2009) and Grell convective parameterization (Grell and Devenyi 2002) were used for microphysics and cumulus parameterization. The cumulus scheme was not applied for domains of 4 and $1.3 \mathrm{~km}$ horizontal resolution. The Mellor-Yamada-Janjic scheme was used as the PBL option (Janjić et al. 1994). The outermost domain of $36 \mathrm{~km}$ horizontal grid resolution was independently simulated with nudging for wind, temperature, and water vapor fields to NCEP/National Center for Atmospheric Research (NCAR) final analysis data for all vertical layers, where the analysis data has $1^{\circ}$ spatial and $6 \mathrm{~h}$ temporal resolution (NCEP/NCAR 2021). For inner domains of 12,4, and $1.3 \mathrm{~km}$, the nudging was applied toward the Meso-scale Analysis (MANAL) by the Japan Meteorological Agency (JMA), which has a grid spacing of $5 \mathrm{~km}$ spatial and $3 \mathrm{~h}$ temporal variation.

The emission dataset was created using anthropogenic emissions from Hemispheric Transport of Air Pollution (HTAP) version 2.2 (Janssens-Maenhout et al. 2015) over Asia and the PM $_{2.5}$ emission inventory for fiscal year 2015 (defined as April 2015 to March 2016) developed by the Ministry of Environment (MOE 2019) over Japan, biogenic emissions from the Model of Emissions of Gases and Aerosols from Nature (MEGAN) (Guenther et al. 2012), emissions from biomass burning in the Global Fire Emissions Database (GFED) version 4.1 (van der Werf et al. 2017), emissions from 16 volcanoes in Japan from observational data obtained by the Japan Meteorological Agency (JMA 2021), and emissions from 33 degassing volcanoes in Russia, India, Indonesia, Philippines, Papua New Guinea, and Northern Mariana Islands constrained by satellite measurement (Carn et al. 2017). Because anthropogenic emissions from China have shown dramatic changes in recent years (Irie et al. 2016; Itahashi et al. 2019), Chinese emissions from each sector were adjusted to the estimated values for 2015 (Zheng et al. 2018). The $\mathrm{NO}_{x}$ emissions used in this study are shown in Fig. 2. Gas chemistry in the CMAQ was used for SAPRC07 (Hutzell et al. 2011) and aerosol chemistry in the CMAQ was used for aero6 with non-volatile primary organic aerosol (Simon and Bhave 2012). The lateral boundary condition 
for the outermost domain was taken from the global model of the Model for Ozone and Related Chemical Tracers (MOZART) version 4 (Emmons et al. 2010), and the nested domains used the outer domains simulation results for the lateral boundary condition. The default CMAQ profile was used for the initial condition. The WRF and CMAQ simulations were conducted from 2 November 2015 in order to set a oneweek spin-up time for removing the effect of the initial conditions.

For assessing model performance, three statistical metrics were used: correlation coefficient (R), normalized mean bias (NMB), and normalized mean error (NME). These are defined as follows:

$$
\begin{aligned}
& R=\frac{\sum_{1}^{N}\left(O_{i}-\bar{O}\right)\left(M_{i}-\bar{M}\right)}{\sqrt{\sum_{1}^{N}\left(O_{i}-\bar{O}\right)^{2}} \sqrt{\sum_{1}^{N}\left(M_{i}-\bar{M}\right)^{2}}} \\
& N M B=\frac{\sum_{1}^{N}\left(M_{i}-O_{i}\right)}{\sum_{1}^{N} O_{i}} \\
& N M E=\frac{\sum_{1}^{N}\left|M_{i}-O_{i}\right|}{\sum_{1}^{N} O_{i}}
\end{aligned}
$$

where $N$ is the total number of paired observations $(0)$ and models $(M)$, and these averages are respectively denoted as $\bar{O}$ and $\bar{M}$.

\section{Results And Discussion}

This section presents the results and discusses the findings of this study. Section 3.1 presents the temporal variation of $\mathrm{NO}_{2}$ concentration at the surface level using ground-based observation by AEROS, and Sect. 3.2 presents the temporal variation of aloft $\mathrm{NO}_{2}$ concentration based on MAX-DOAS. The model validations are also presented. Section 3.3 examines the diurnal variation of $\mathrm{NO}_{2}$ concentration at the surface and aloft. Section 3.4 considers the reason for episodic high concentrations of $\mathrm{NO}_{2}$ based on the meteorological field. Finally, Sect. 3.5 provides the correspondence between surface and aloft $\mathrm{NO}_{2}$ pollution as analyzed by the well-validated modeling simulation.

\subsection{Temporal variation of surface $\mathrm{NO}_{2}$ concentration}

The overall modeling performance during Chiba-Campaign 2015 was validated using ground-based AEROS observation. A comparison of the surface observation by AEROS located within $24 \mathrm{~km}$ (maximum horizontal distance measured by MAX-DOAS, see Fig. 1) of Chiba University and the model at the surface level is shown as a scatterplot in Fig. 3. During Chiba-Campaign 2015, surface $\mathrm{NO}_{2}$ concentration around Chiba University ranged mostly within 30 ppbv (dense circles in Fig. 3), and sometimes exhibited high concentrations of up to 70 ppbv. Over 20,000 pairs of observed and modeled hourly $\mathrm{NO}_{2}$ concentration, $\mathrm{R}$ of 0.50 showed a moderate linear correlation, NMB was $+9.8 \%$, and NME was $55.9 \%$. It has been reported 
that R ranged from 0.51 to 0.92 and NME ranged from $25-85 \%$ over China based on model results using three different emission datasets and their evaluation against the various surface observation categories (Liu et al. 2018). The Model Inter-Comparison Study for Asia (MICS-Asia) Phase III reported that R was $0.02-0.70$ and NMB ranged between $-44 \%$ and $+36 \%$ (Kong et al. 2020). The results of this study demonstrate that the model could generally capture the surface $\mathrm{NO}_{2}$ concentration around Chiba University through Chiba-Campaign 2015.

For the purpose of detailed comparison using ground-based AEROS observations, the modeling performance at ground-based AEROS observations located along the path of 4AZ-MAX-DOAS measurements (see Fig. 1) was further evaluated. The temporal variations during Chiba-Campaign 2015 at these AEROS sites are shown in Fig. 4. Hereinafter, timeseries data are shown as local time (LT) which defined as Universal Time Coordinate (UTC) $+9 \mathrm{~h}$. In the north, east, west, and south directions, a total of $5,3,1$, and 4 sites were located along the measurement paths of 4AZ-MAX-DOAS, respectively. These AEROS sites are named in order of closeness from Chiba University in each direction (see Fig. 4). High $\mathrm{NO}_{2}$ concentration is defined as greater than $30 \mathrm{ppbv}$ in this discussion, and is denoted by a yellow highlight at each site in Fig. 4. In the north direction (green in Fig. 4), R was around 0.5, NMB was within \pm $25 \%$, and NME was within $50 \%$. At the N2 site, classified as an AEROS RAPMS site, the model performance was lower than that at other APMS sites in the north direction. Because the N1 and N2 sites are located close together, the modeling results were taken from same grid point in this comparison. Compared with the modeling performance found at N1, all statistical scores were worse, and model underestimation was identified at N2. This result indicates that even when the finer horizontal resolution of $1.3 \mathrm{~km}$ was used for air quality modeling, it was difficult to capture local $\mathrm{NO}_{2}$ pollution mainly caused by automobile sources. In the east direction (blue in Fig. 4), the comparison at the E2 and E3 sites which are classified as AEROS APMS sites was better than at the E1 site which was classified as an AEROS RAPMS site in terms of NMB and NME. The model also underestimated $\mathrm{NO}_{2}$ concentration at RAPMS sites, and this result in the east direction was similar to that found in the north direction. In the west direction (orange in Fig. 4), only a single APMS site close to Chiba University was available because this direction covers the Tokyo Bay area. The model performance at the W1 site was comparable to that at the N3 and E3 sites. In the south direction (red in Fig. 4), at the S1 site which is classified as an AEROS RAPMS site located near Chiba University, the model performance was mostly comparable to that found in the other directions. In contrast, the model generally tended to overestimate the surface $\mathrm{NO}_{2}$ pollution at the other sites S2, S3, and S4 in the south direction. At the S2, S3, and S4 sites, the model overestimation was suggested from NMB exceeding $+50 \%$. As indicated from the temporal variation at S2, S3, and S4, the model overestimation was seen during 15-16, 17-18, and 20-21 November 2015, when $\mathrm{NO}_{2}$ concentrations were generally high. Because of this tendency of the model for overestimation in the south direction, model underestimation at RAPMS sites as found in the north and east directions was not detected. Based on these detailed comparisons of the temporal variation at AEROS sites located along the path of $4 A Z-A M A X-D O A S$, it was found that the model had some difficulties with underestimation when capturing local air pollution caused by automobile sources at RAPMSs sites in the north and east direction and overestimation in the south direction. Overall, the model generally captured 
the temporal variation of surface $\mathrm{NO}_{2}$ pollution around Chiba University along the path of 4AZ-MAXDOAS.

From the temporal variation shown in Fig. 4, surface $\mathrm{NO}_{2}$ concentration typically showed diurnal variation with minima during the daytime and maxima during the nighttime. During Chiba-Campaign 2015, elevated $\mathrm{NO}_{2}$ concentrations were detected on 9, 15, 16, 17-18, and 20-21 November 2015, as distinguished by yellow highlights in Fig. 4. For the elevated $\mathrm{NO}_{2}$ concentrations on 9, 15, and 16 November, a short-time peak was found during the nighttime, whereas 17-18 and 20-21 November exhibited continuously higher concentrations over the whole day as the diurnal variations changed such that there was no daytime minima. Diurnal variation and episodic peaks of $\mathrm{NO}_{2}$ concentration are respectively discussed in Sect. 3.3 and 3.4 .

\subsection{Temporal variation of aloft $\mathrm{NO}_{2}$ concentration}

The temporal variation of aloft $\mathrm{NO}_{2}$ concentration obtained by comparing 4AZ-MAX-DOAS and model results averaged over $0-1 \mathrm{~km}$ are shown in Fig. 5 . The horizontal measurement distance of MAX-DOAS is also plotted. Since the horizontal distance viewed by MAX-DOAS is dependent on aerosol pollution, it varied from 4 to $24 \mathrm{~km}$, with longer distances on clean days, such as during lower $\mathrm{NO}_{2}$ concentration periods on 11-13 November 2015. The modeled $\mathrm{NO}_{2}$ concentration within $24 \mathrm{~km}$ from Chiba University from model results is shown as the range in Fig. 5, and statistical analysis of the comparison with MAXDOAS observation was conducted using the data within the observed horizontal distance to match the view by MAX-DOAS. From the range of modeled $\mathrm{NO}_{2}$ concentration within 4-24 km from Chiba University, the modeled $\mathrm{NO}_{2}$ pollution range within the horizontal direction of MAX-DOAS was generally small except for pollution events. This result implies that $\mathrm{NO}_{2}$ pollution around Chiba University was generally dominated by regional-scale broad pollution over the greater Tokyo area. In the north, east, and west directions, the range of modeled $\mathrm{NO}_{2}$ concentration was small except for high concentration events on $9,15,16,17-18$, and 20-21 November 2015. Because MAX-DOAS observation was limited to during the daytime, the higher $\mathrm{NO}_{2}$ concentrations at night on 9,15 , and 16 November were not measured. However, the cases of episodic high concentration on 17-18 and 20-21 November, which were characterized by continuous high concentration, corresponded well between MAX-DOAS and aloft model results. The modeling performance for the north, east, and west directions were $\mathrm{R}$ in the range $0.36-0.56$, NMB around $+20 \%$, and NME around $50 \%$. These results are comparable with the surface results. In the south direction, the range of modeled $\mathrm{NO}_{2}$ concentration was also large during episodic $\mathrm{NO}_{2}$ pollution events, but also showed larger variation throughout Chiba-Campaign 2015 compared with the other directions. As found in the surface comparison, the model also tended to overestimate aloft $\mathrm{NO}_{2}$ concentration in the south direction. Although the value of NMB was larger in the south direction than in the other directions, NME was comparable and $\mathrm{R}$ was better compared with the other directions. In summary, it was validated that the model captured aloft $\mathrm{NO}_{2}$ concentration through comparison with 4AZ-MAX-DOAS observations. 


\subsection{Diurnal variation of surface and aloft $\mathrm{NO}_{2}$ concentrations}

Sections 3.1 and 3.2 evaluated the temporal variations of surface and aloft $\mathrm{NO}_{2}$ concentrations and confirmed that the modeling system generally captured surface and aloft $\mathrm{NO}_{2}$ pollution. The diurnal variations are further analyzed here in Sect. 3.3. The surface and aloft diurnal variations in $\mathrm{NO}_{2}$ concentration averaged during Chiba-Campaign 2015 for the direction observed by 4AZ-MAX-DOAS are presented in Fig. 6. From the comparison at the surface level (left side of Fig. 6), the model could capture the observed diurnal variation, which consisted of a morning peak, subsequent decline during the daytime, and then an evening peak. In detail, the observed values showed morning maxima during 8 to 9 AM whereas the model showed morning maxima at the sunrise time of $6 \mathrm{AM}$. In contrast, for the evening peak seen after the sunset time of 5 PM, the timing of maxima was well reproduced by the model, particularly in the north and east directions. As found from the analysis of temporal variations shown in Fig. 3, the model tended to overestimate in the south direction, and this modeling overestimation was identified during the nighttime from the analysis of diurnal variation at the surface level. Apart from this difficulty, the model can capture the diurnal variation of $\mathrm{NO}_{2}$ concentration at the surface level. The evening peak was a good match between surface observation and the model whereas the morning peak showed a slight difference in timing. This suggests that investigation into the chemical mechanisms related to NOx and sunlight is needed in future research.

In the comparison of aloft $\mathrm{NO}_{2}$ concentration, all MAX-DOAS observations are plotted as light colors, and $1 \mathrm{~h}$ averaged data are plotted as dark colors (right side of Fig. 6). The hourly averages at 7 AM and 4 PM were not well counted (1-3 times through Chiba-Campaign-2015) and hence the $1 \mathrm{~h}$ averaged plot is not shown for these times. All 4AZ-MAX-DOAS showed a slight decrease in concentration during the daytime around noon, and the model reproduced these observations for all directions. As with the surface concentration in the south direction, the aloft $\mathrm{NO}_{2}$ concentration in the south direction was also overestimated. However, the temporal variation consisting of a drop around noon was captured. Based on this comparison, it was concluded that the diurnal variations were well reproduced by the model at both the surface and aloft. To our knowledge, the diurnal variation in surface and aloft $\mathrm{NO}_{2}$ concentrations has not been adequately compared in detail, and this study provides comprehensive analyses for verifying the air quality modeling performance at both the surface and aloft. Considering the better modeling performance in the north and east directions than in the south direction, one possible reason for the difficulty in modeling may be issues in the emission estimates. The coastline of the Tokyo Bay area has many industrial and power plants, which have relatively high stack heights, and the impact of these may be observed over the south direction from Chiba University. Because $\mathrm{NO}_{2}$ concentration was overestimated both at the surface and aloft, the emission amount itself might be overestimated. Moreover, chemical and physical processes related to NOx emissions from point sources could be related to the emission amount itself. These points should be explored in the future to improve the modeling performance around the greater Tokyo area. 


\subsection{Episodic peaks in $\mathrm{NO}_{2}$ concentration}

The diurnal variation presented in Sect. 3.3 was the averaged characteristics during Chiba-Campaign 2015. As shown in the temporal variation presented in Figs. 4 and 5, some episodic peaks in $\mathrm{NO}_{2}$ concentration were detected on 9, 15, 16, 17-18, and 20-21 November 2015. Here in Sect. 3.4, the reason for the increased $\mathrm{NO}_{2}$ concentration is considered based on the meteorological field. The meteorological parameters measured by the Automated Meteorological Data Acquisition System (AMeDAS) of the Chiba special area meteorological observatory, which is located near Chiba University (see Fig. 1), and its modeling performance are shown in Fig. 7. In this figure, high concentrations of $\mathrm{NO}_{2}$ of more than 20 ppbv are also indicated by yellow highlights based on the averaged concentration of APMS sites located along the path of 4AZ-MAX-DOAS for clarity (see also Fig. 4). The meteorological field was well reproduced by the modeling system throughout the Chiba-Campaign 2015. The air temperature ( Fig. 7a), ranged from $10^{\circ} \mathrm{C}$ to $20^{\circ} \mathrm{C}$ with clear diurnal variation of daytime maxima. During Chiba-Campaign 2015, there were drops in temperature on 13 and 20 November 2015. The observed hourly daylight duration and modeled solar radiation reaching the surface level are plotted in Fig. $7 \mathrm{~b}$. These indicate the weather conditions, and the results show that 10,13-14, and 20 November 2015 had cloudy conditions. Rainy conditions were clarified by analyses of precipitation as shown in Fig. $7 \mathrm{c}$ and relative humidity as shown in Fig. 7d. During Chiba-Campaign 2015, precipitation events occurred on 9, 10, 14, 15, and 19 November. In these precipitation events, relative humidity also exhibited high values of close to $100 \%$. Wind components are presented as wind speed in Fig. 7e and wind direction in Fig. 7f. The wind speed was generally around $5 \mathrm{~m} / \mathrm{s}$ and sometimes reached $10 \mathrm{~m} / \mathrm{s}$, and it was found that the high $\mathrm{NO}_{2}$ concentration (yellow highlight) correlated well with weak wind speed. Throughout Chiba-Campaign 2015 , wind was in the north $\left(0^{\circ}\right)$ to east $\left(90^{\circ}\right)$ direction. However, wind changes to the west $\left(270^{\circ}\right)$ or northwest direction were found which corresponded to intense emission sources around the Tokyo Bay area. Therefore, the stagnant conditions in the transport of air mass from the dense emission sources around the Tokyo Bay area are thought to be the reason for increased $\mathrm{NO}_{2}$ concentration in terms of meteorological conditions. The highest $\mathrm{NO}_{2}$ concentration was seen on 17-18 November and the longest continuous $\mathrm{NO}_{2}$ concentration was found during 20-21 November with difference diurnal patterns; these are further discussed in Sect. 3.5.

\subsection{Correspondence between surface and aloft $\mathrm{NO}_{2}$ pollution}

Section 3.1 and 3.2 validated the modeling at the surface and aloft and Sect. 3.3 evaluated the diurnal variation at the surface and aloft by combining surface AEROS and aloft MAX-DOAS measurements. Section 3.4 examined the meteorological field causing episodic high $\mathrm{NO}_{2}$ concentrations, and stagnant conditions with a westerly wind direction can be considered as a reason for the high concentrations. Finally, here in Sect. 3.5, the relationship between surface and aloft $\mathrm{NO}_{2}$ pollution was analyzed based on well-evaluated modeling simulation results. The hourly $\mathrm{NO}_{2}$ concentration averaged during Chiba- 
Campaign 2015 is plotted at each hour for surface and aloft in Fig. 8. Throughout the day, high $\mathrm{NO}_{2}$ concentration was found over the Tokyo Bay area both at the surface and aloft. As seen for the diurnal variation reported in Fig. 6 , the range of diurnal variation was larger at the surface than aloft. At the surface, high concentrations of greater than 20 ppbv (shown as orange to red in Fig. 8) were distributed over eastern Tokyo and Kanagawa prefecture and western Chiba prefecture, but these areas of high concentration were limited to only along the coastline of Tokyo Bay area from 10-14 LT. Compared with the features of the spatial distribution pattern of the high concentration area found at the surface, a moderately high concentration (shown as green in Fig. 8) was continuously seen aloft through the day. In order to find the relationship between the surface and aloft $\mathrm{NO}_{2}$ concentrations, linear regression was performed using all grid point data over this modeling domain for surface and aloft $\mathrm{NO}_{2}$ concentrations. The results are listed in Table 1 with domain averaged concentration (mean \pm standard deviation), slope, intercept, and R. The results show clear linearity with R exceeding 0.918 through the day. The value of slope in the linear regression was around 0.4 during the nighttime and reached around 0.55 during the daytime. This result indicates that the aloft concentration was linearly scaled to 0.4 times the surface concentration during the nighttime and also linearly scaled to 0.55 times the surface level around noon (10 LT to $14 \mathrm{LT}$ ). The higher fraction during the daytime was due to the well-mixed air pollution within the PBL. This linear relationship between surface and aloft $\mathrm{NO}_{2}$ concentrations through the day was a key finding of this study; and this relation variated with a lower scaling value of around 0.4 during the nighttime and a higher value reaching 0.55 during the daytime. 
Table 1

Hourly correspondence between modeled surface and aloft $\mathrm{NO}_{2}$ concentrations (averaged over $0-1 \mathrm{~km}$ )

\begin{tabular}{|llllll|}
\hline LT & Surface & $\mathbf{0}-1 \mathrm{~km}$ & Slope & Intercept & $\mathbf{R}$ \\
\hline 0 & $8.73 \pm 7.00$ & $4.37 \pm 2.88$ & 0.398 & 0.897 & 0.966 \\
\hline 1 & $8.33 \pm 6.68$ & $4.15 \pm 2.82$ & 0.409 & 0.753 & 0.968 \\
\hline 2 & $8.19 \pm 6.72$ & $4.03 \pm 2.91$ & 0.418 & 0.604 & 0.966 \\
\hline 3 & $8.31 \pm 6.91$ & $4.00 \pm 3.03$ & 0.421 & 0.503 & 0.959 \\
\hline 4 & $8.72 \pm 7.04$ & $4.08 \pm 3.09$ & 0.415 & 0.459 & 0.945 \\
\hline 5 & $9.65 \pm 7.45$ & $4.28 \pm 3.14$ & 0.391 & 0.511 & 0.926 \\
\hline 6 & $10.99 \pm 8.10$ & $4.65 \pm 3.26$ & 0.370 & 0.577 & 0.918 \\
\hline 7 & $10.57 \pm 7.44$ & $4.67 \pm 3.11$ & 0.391 & 0.536 & 0.933 \\
\hline 8 & $9.50 \pm 6.59$ & $4.64 \pm 3.08$ & 0.447 & 0.394 & 0.957 \\
\hline 9 & $8.63 \pm 6.13$ & $4.63 \pm 3.10$ & 0.493 & 0.381 & 0.972 \\
\hline 10 & $7.84 \pm 5.80$ & $4.55 \pm 3.17$ & 0.531 & 0.382 & 0.975 \\
\hline 11 & $7.15 \pm 5.42$ & $4.39 \pm 3.12$ & 0.558 & 0.397 & 0.969 \\
\hline 12 & $6.72 \pm 4.95$ & $4.23 \pm 2.92$ & 0.567 & 0.417 & 0.962 \\
\hline 13 & $6.76 \pm 4.89$ & $4.26 \pm 2.86$ & 0.561 & 0.462 & 0.958 \\
\hline 14 & $7.12 \pm 5.19$ & $4.44 \pm 2.98$ & 0.548 & 0.536 & 0.954 \\
\hline 15 & $8.12 \pm 6.04$ & $4.91 \pm 3.32$ & 0.523 & 0.654 & 0.951 \\
\hline 16 & $10.04 \pm 7.83$ & $5.52 \pm 3.87$ & 0.469 & 0.809 & 0.950 \\
\hline 17 & $11.24 \pm 8.96$ & $5.64 \pm 3.99$ & 0.424 & 0.881 & 0.952 \\
\hline 18 & $11.44 \pm 8.85$ & $5.58 \pm 3.81$ & 0.408 & 0.913 & 0.947 \\
\hline 19 & $11.61 \pm 8.66$ & $5.49 \pm 3.53$ & 0.383 & 1.038 & 0.940 \\
\hline 20 & $11.47 \pm 6.34$ & $5.32 \pm 3.28$ & 0.371 & 1.063 & 0.942 \\
\hline 21 & $10.79 \pm 7.93$ & $5.03 \pm 3.17$ & 0.380 & 0.933 & 0.950 \\
\hline 22 & $9.82 \pm 7.69$ & $4.71 \pm 3.11$ & 0.388 & 0.902 & 0.959 \\
\hline 23 & $9.23 \pm 7.60$ & $4.53 \pm 3.10$ & 0.393 & 0.903 & 0.964 \\
\hline Note: Total grid numbers in modeling domain are 11025. \\
\hline
\end{tabular}


The previous discussion focused on the diurnal variation. Because episodic high concentrations were found during Chiba-Campaign 2015, the daily-averaged surface and aloft $\mathrm{NO}_{2}$ concentrations over the modeling domain were further analyzed in order to investigate the temporal change in the linear relationship between surface and aloft. The daily average was based on the average over 0-23 LT. The spatial mappings of each day are plotted in Fig. 9, and the period average during Chiba-Campaign 2015 are also plotted at the bottom-right corner of Fig. 9. $\mathrm{NO}_{2}$ concentration showed day-to-day variation and the spatial distribution pattern between surface and aloft are in generally good agreement. For example, in the case of high $\mathrm{NO}_{2}$ concentration on 9 November 2015 as suggested by temporal variation (Figs. 4 and 5), the higher $\mathrm{NO}_{2}$ concentration stretched into northern Chiba and up to Ibaraki and Saitama prefectures at the surface level, and this feature was also seen aloft. On 9 November 2015, a southerly wind close to $10 \mathrm{~m} / \mathrm{s}$ prevailed (Fig. 7). In another case of high $\mathrm{NO}_{2}$ concentration during 20-21 November 2015, higher $\mathrm{NO}_{2}$ concentrations were found over a broad area of Kanagawa prefecture, eastern Tokyo, and western Chiba prefecture on these days at the surface, and the aloft concentration also showed a similar spatial distribution. To confirm these characterizations of the surface and aloft $\mathrm{NO}_{2}$ pollution, linear regression was performed for each day and period average in the same way as for the diurnal variation listed in Table 1. The result for daily and period averages are listed in Table 2. The daily averaged concentrations varied from 6 ppbv to 15 ppbv during Chiba-Campaign 2015. In spite of this variation in concentration, comparison of surface and aloft found an $\mathrm{R}$ exceeding 0.924 , which suggests clearly linear correspondence between surface and aloft $\mathrm{NO}_{2}$ concentrations through the ChibaCampaign 2015. Although the intercept of the linear regression ranged between 0.0 and 0.75 , it was found that the slope ranged within $0.4-0.5$ except on 16 November 2015 when it was 0.37 . This result indicates that the aloft $\mathrm{NO}_{2}$ concentration is linearly scaled to $0.4-0.5$ times the surface $\mathrm{NO}_{2}$ concentration on both clean and polluted days. 
Table 2

Daily/period averaged correspondence between modeled surface and aloft $\mathrm{NO}_{2}$ concentration (averaged over $0-1 \mathrm{~km}$ )

\begin{tabular}{|llllll|}
\hline Date & Surface & $\mathbf{0 - 1} \mathbf{~ k m}$ & Slope & Intercept & $\mathbf{R}$ \\
\hline 9 November 2015 & $9.49 \pm 9.21$ & $4.65 \pm 4.69$ & 0.483 & 0.061 & 0.949 \\
\hline 10 November 2015 & $9.04 \pm 6.87$ & $5.15 \pm 3.50$ & 0.486 & 0.752 & 0.954 \\
\hline 11 November 2015 & $6.13 \pm 6.00$ & $3.46 \pm 3.03$ & 0.478 & 0.530 & 0.946 \\
\hline 12 November 2015 & $5.97 \pm 6.31$ & $3.15 \pm 3.16$ & 0.469 & 0.361 & 0.933 \\
\hline 13 November 2015 & $6.61 \pm 6.58$ & $3.40 \pm 3.28$ & 0.464 & 0.329 & 0.932 \\
\hline 14 November 2015 & $6.17 \pm 6.26$ & $3.28 \pm 3.17$ & 0.478 & 0.329 & 0.944 \\
\hline 15 November 2015 & $13.36 \pm 8.65$ & $6.62 \pm 4.23$ & 0.470 & 0.332 & 0.961 \\
\hline 16 November 2015 & $9.30 \pm 8.51$ & $4.17 \pm 3.40$ & 0.371 & 0.714 & 0.928 \\
\hline 17 November 2015 & $12.11 \pm 10.11$ & $6.19 \pm 5.16$ & 0.483 & 0.347 & 0.946 \\
\hline 18 November 2015 & $12.97 \pm 7.66$ & $6.54 \pm 3.96$ & 0.496 & 0.107 & 0.959 \\
\hline 19 November 2015 & $5.50 \pm 5.44$ & $2.95 \pm 2.62$ & 0.448 & 0.485 & 0.927 \\
\hline 20 November 2015 & $15.48 \pm 12.15$ & $7.34 \pm 6.22$ & 0.474 & -0.001 & 0.926 \\
\hline 21 November 2015 & $8.97 \pm 7.13$ & $4.48 \pm 3.24$ & 0.425 & 0.674 & 0.935 \\
\hline 22 November 2015 & $7.81 \pm 7.81$ & $4.01 \pm 3.90$ & 0.461 & 0.409 & 0.924 \\
\hline Period average & $9.20 \pm 6.74$ & $4.67 \pm 3.06$ & 0.436 & 0.665 & 0.961 \\
\hline Note: The total number of grid cells in the modeling domain is 11025. & \\
\hline
\end{tabular}

Finally, the vertical profile of $\mathrm{NO}_{2}$ concentration from the model simulation is shown in Fig. 10. This curtain plot shows the vertical structure for $\mathrm{NO}_{2}$ concentration during the Chiba-Campaign 2015 with modeled PBL height at the grid point of Chiba University. The PBL height showed variation from the near surface up to $1.0 \mathrm{~km}$ with a general diurnal profile featuring daytime maxima. As discussed for temporal variations in the surface and aloft $\mathrm{NO}_{2}$ concentrations, high $\mathrm{NO}_{2}$ concentration events were found on 9 , $15,16,17-18$, and 20-21 November 2015. The vertical profiles show that high $\mathrm{NO}_{2}$ concentrations (red in Fig. 10) were mostly limited within $0.2 \mathrm{~km}$, and also within the PBL. In the vertical direction, $\mathrm{NO}_{2}$ concentrations were lower than 5 ppbv (light blue in Fig. 10) above $0.5 \mathrm{~km}$, even though PBL height sometimes reached up to $1.0 \mathrm{~km}$. Note the highest $\mathrm{NO}_{2}$ concentration on 17-18 November 2015 and the longest continuous $\mathrm{NO}_{2}$ concentration during 20-21 November 2015. During these events, the PBL height was close to the near-surface level. Taking into consideration analyses of the meteorological field as shown in Fig. 7, the stagnant air mass with weak wind speed and cloudy conditions with a lower PBL close to the surface were possible factors causing the increased $\mathrm{NO}_{2}$ concentration. Through the 
validated modeling performance, the vertical $\mathrm{NO}_{2}$ profile with its important connection to the $\mathrm{PBL}$ height was clarified.

\section{Conclusions}

Surface and aloft $\mathrm{NO}_{2}$ concentrations were extensively investigated by comprehensive analyses of the ground-based observation network of AEROS and aloft MAX-DOAS measurement, and bridged by an air quality modeling system with a horizontal grid resolution of $1.3 \mathrm{~km}$. We presented detailed analyses on surface and aloft $\mathrm{NO}_{2}$ concentrations targeting the period of the Chiba-Campaign 2015 conducted from 9 to 23 November 2015. The evaluations showed that the present air quality modeling system can generally capture the observed behavior of both surface and aloft $\mathrm{NO}_{2}$ pollution. Some difficulties in the current modeling system were also found. One issue is model underestimation when capturing roadside $\mathrm{NO}_{2}$ pollution with a horizontal grid resolution of $1.3 \mathrm{~km}$, and the other is model overestimation in the south direction from Chiba University. For the latter, this is thought to be related to the emission estimation over the Tokyo Bay area, which has intense sources from industrial and power plants. From the comparison on diurnal variation patterns, a slight difference in morning peak of $\mathrm{NO}_{2}$ concentration was also found, and further investigation of daytime chemical mechanisms related to NOx may help refine our understanding of this. Based on the comparison between modeled surface and aloft $\mathrm{NO}_{2}$ concentrations, it was found that aloft $\mathrm{NO}_{2}$ concentration linearly scaled to $0.4-0.5$ times the surface $\mathrm{NO}_{2}$ concentration during both clean and polluted days, with the higher value of 0.55 reached around noon due to the well-mixed air mass within the PBL. This study gave important suggestions for fostering our understanding of the vertical profiles of $\mathrm{NO}_{2}$ over the greater Tokyo area.

Horizontal coverage based on ground-based measurements is sparse in terms of spatial coverage. Space-based satellite measurement can provide a broad spatial distribution of air pollutants. Although previous sensors have been limited in terms of spatial resolution for the purpose of detecting urban-scale air pollution (Itahashi et al. 2014; Irie et al. 2016), the state-of-the-science sensor of TROPOspheric Monitoring Instrument (TROPOMI) onboard the Sentinel-5 precursor satellite launched on 13 October 2017 can provide finer spatial resolution below $10 \mathrm{~km}$ (Griffin et al. 2019). Although the use of these recent satellite observations may be helpful for understanding the spatial distribution patterns, the values measured by the satellite are vertically integrated concentrations. Comprehensive analysis of surface and aloft observation as conducted in this study combined with this kind of satellite observation with finer resolution is required for future studies. From this perspective, because cloudy and lower PBL height conditions which lead to increased $\mathrm{NO}_{2}$ pollution as found in this study are unfavorable for satellite measurements, accurate modeling is required to bridge the missing information among surface, aloft, and satellite measurements. In addition, a clear linear relationship between surface and aloft $\mathrm{NO}_{2}$ concentrations was limited to the analysis of Chiba-Campaign 2015 conducted in autumn, and analysis of other seasons is needed for further understanding of $\mathrm{NO}_{2}$ behavior at the surface and aloft. 


\section{Abbreviations}

4AZ-MAX-DOAS: four different azimuth-viewing MAX-DOAS; AEROS: Atmospheric environmental regional observation system; AMeDAS: Automated Meteorological Data Acquisition System; APMSs: ambient air pollution monitoring stations; AQS: Air Quality Standard; CINDI: Cabauw intercomparison campaign of nitrogen dioxide measuring Instruments; CMAQ: Community Multiscale Air Quality; DOAS: Differential optical absorption spectroscopy; GFED: Global Fire Emissions Database; HTAP: Hemispheric Transport of Air Pollution; JM2: Japanese MAX-DOAS profile retrieval algorithm, version 2; JMA: Japan Meteorological Agency; LT: local time; M: models; MANAL: Meso-scale Analysis; MAX-DOAS: Multi-axis differential optical absorption spectroscopy; MEGAN: Model of Emissions of Gases and Aerosols from Nature; MOZART: Model for Ozone and Related Chemical Tracers; NCAR: National Center for Atmospheric Research; NCEP: National Centers for Environmental Prediction; NMB: normalized mean bias; NME: normalized mean error; $\mathrm{NO}$ : nitric oxide; $\mathrm{NO}_{2}$ : nitrogen dioxide; NOx: nitrogen oxides; O: observations; $\mathrm{O}_{\mathrm{x}}$ : oxidants; PBL: Planetary boundary layer; $\mathrm{PM}_{2.5}$ : particulate matter with aerodynamic diameter less than to $2.5 \mu \mathrm{m}$; R: correlation coefficient; RAPMSs: roadside air pollution monitoring stations; RHw: Relative humidity over water; RRTMG: rapid radiative transfer model for global climate models; TROPOMI: Tropospheric monitoring instrument; UTC: Universal Time Coordinate; UV: ultraviolet; WRF: Weather Research and Forecasting

\section{Declarations}

\section{Availability of data and material}

The datasets used and analyzed during the current study are available the corresponding author on request.

\section{Competing interests}

The authors declare that they have no competing interest.

\section{Funding}

This research was supported by the Environment Research and Technology Development Fund (grant numbers JPMEERF20192001 and JPMEERF20215005) of the Environmental Restoration and Conservation Agency of Japan, JSPS KAKENHI (grant numbers JP19H04235 and JP20H04320), and the JAXA 2nd research announcement on the Earth Observations (grant number 19RT000351).

\section{Authors' contributions}


SI carried out the numerical modeling simulations, conducted the evaluation with the observation dataset, designed the analyses, and wrote the paper. HI performed the MAX-DOAS observation and its analyses, proposed this topic, helped write the paper, and designed the study. All authors read and approved the final manuscript.

\section{Authors' information}

There is no additional author's information.

\section{Acknowledgements}

We are grateful for the use of the MANAL dataset distributed by the Japan Meteorological Business Support Center (JMBSC).

\section{References}

1. Carn SA, Fioletov VE, McLinden CA, Li C, Krotkov NA (2017) A decade of global volcanic $\mathrm{SO}_{2}$ emissions measured from space. Sci Rep 7:44095. doi: 10.1038/srep44095

2. Choi Y, Kanaya Y, Takashima H, Irie H, Park K, Chong J (2021) Long-term variation in the tropospheric nitrogen dioxide vertical column density over Korea and Japan from the MAX-DOAS Network, 20072017. Remote Sens 13:1937. doi: 10.3390/rs13101937

3. Grell GA, Dévényi D (2002) A generalized approach to parameterizing convection combining ensemble and data assimilation techniques. Geophys Res Lett 29:1693. doi: 10.1029/2002GL015311

4. Griffin D, McLinden CA, Boersma F, Bourassa A, Dammers E, Degenstein D, Eskes H, Fehr L, Fioletov V, Hayden K, Kharol SK, Li S-M, Makar P, Martin RV, Mihele C, Mittermeier RL, Krotkov N, Sneep M, Lamsal LN, Ter Linden M, van Geffen J, Veefkind P, Wolde M, Zhao X (2019) High-resolution mapping of nitrogen dioxide with TROPOMI: First results and validation over the Canadian oil sands. Geophys Res Lett 46:1049-1060. doi: 10.1029/2018GL081095

5. Guenther AB, Jiang X, Heald CL, Sakulyanontvittaya T, Duhl T, Emmons LK, Wang X (2012) The Model of Emissions of Gases and Aerosols from Nature version 2.1 (MEGAN2.1). An extended and updated framework for modeling biogenic emissions. Geosci Model Dev 5: 1471-1492.

6. Hönninger G, Platt U (2002) Observations of $\mathrm{BrO}$ and its vertical distribution during surface ozone depletion at Alert. Atmos Environ 36:2481-2489. doi: 10.1016/S1352-2310(02)00104-8

7. Hönninger G, von Friedeburg C, Platt U (2004) Multi axis differential optical absorption spectroscopy (MAX-DOAS). Atmos Chem Phys 4:231-254. doi: 10.5194/acp-4-231-2004

8. Iacono MJ, Delamere JS, Mlawer EJ., Shephard MW, Clough SA, Collins WD (2008) Radiative forcing by long-lived greenhouse gases: Calculations with the AER radiative transfer models. J Geophys Res 113:D13103. doi: 10.1029/2008JD009944 
9. Hutzell WT, Luecken DJ, Appel WK, Carter WP (2011) Interpreting predictions from the SAPRC07 mechanism based on regional and continental simulations. Atmos Environ 46: 417-429.

10. Irie H, Hoque HMS, Damiani A, Okamoto H, Fatmi AM, Khatri P, Takamura T, Jarupongsakul T (2019) Simultaneous observations by sky radiometer and MAX-DOAS for characterization of biomass burning plumes in central Thailand in January-April 2016. Atmos Meas Tech 12:599-606. doi: 10.5194/amt-12-599-2019

11. Irie $H$, Kanaya $Y$, Akimoto $H$, Iwabuchi $H$, Shimizu A, Aoki $K$ (2008) First retrieval of tropospheric aerosol profiles using MAX-DOAS and comparison with lidar and sky radiometer measurements. Atmos Chem Phys 8:341-350. doi: 10.5194/acp-8-341-2008

12. Irie H, Muto T, Itahashi S, Kurokawa J, Uno I (2016) Turnaround of tropospheric nitrogen dioxide pollution trends in China, Japan, and South Korea. SOLA 12:170-174 doi: 10.2151/sola.2016-035

13. Irie H, Nakayama T, Shimizu A, Yamazaki A, Nagai T, Uchiyama A, Zaizen Y, Kagamitani S, Matsumi Y. (2015) Evaluation of MAX-DOAS aerosol retrievals by coincident observations using CRDS, lidar, and sky radiometer in Tsukuba, Japan. Atmos Meas Tech 8:2775-2788. doi: 10.5194/amt-8-27752015

14. Irie $H$, Takashima $H$, Kanaya $Y$, Boersma KF, Gast L, Wittrock F, Brunner D, Zhou Y, Van Roozendael M (2011) Eight-component retrievals from ground-based MAX-DOAS observations. Atmos Meas Tech 4:1027-1044. doi: 10.5194/amt-4-1027-2011

15. Irie H, Yonekawa D, Damiani A, Hoque HMS, Sudo K, Itahashi S (2021) Continuous multi-component MAX-DOAS observations for the planetary boundary layer ozone variation analysis at Chiba and Tsukuba, Japan, from 2013 to 2019. Prog Earth Planet Sci 8:31. doi: 10.1186/s40645-021-00424-9

16. Itahashi S (2018). Toward synchronous evaluation of source apportionments for atmospheric concentration and deposition of sulfate aerosol over East Asia. J Geophys Res Atmos 123:29272953. doi: $10.1002 / 2017 J D 028110$

17. Itahashi S, Mathur R, Hogrefe C, Zhang Y (2020) Modeling trans-Pacific transport on tropospheric ozone using hemispheric CMAQ during April 2010 - Part 1: Model evaluation and air mass characterization for stratosphere-troposphere transport. Atmos Chem Phys 20:3373-3396.doi: 10.5194/acp-20-3373-2020

18. Itahashi S, Uno I, Irie H, Kurokawa J-I, Ohara T (2014) Regional modelling of tropospheric $\mathrm{NO}_{2}$ vertical column density over East Asia during the period 2000-2010: Comparison with multisatellite observations. Atmos Chem Phys 14: 3623-3635. doi: 10.5194/acp-14-3623-2014

19. Itahashi S, Yumimoto K, Kurokawa J, Morino Y, Nagashima T, Miyazaki K, Maki T, Ohara T (2019) Inverse estimation of NOx emissions over China and India 2005-2016: Contrasting recent trends and future perspectives. Environ Res Lett 14:124020. doi: 10.1088/1748-9326/ab4d7f

20. Janjić ZI (1994) The step-mountain eta coordinate model: Further developments of the convection, viscous sublayer, and turbulence closure schemes. Month Wet Rev 122:927-945. doi: 10.1175/15200493(1994)122<0927:TSMECM>2.0.C0;2 
21. Janssens-Maenhout G, Crippa M, Guizzardi D, Dentener F, Muntean M, Pouliot G, Keating T, Zhang Q, Kurokawa J, Wankmuller R, Danier van der Gon H, Kuenen JJP, Kilmont Z, Frost G, Darras S, Koffı B, Li M (2015) HTAP_v2.2: a mosaic of regional and global emission grid maps for 2008 and 2010 to study hemispheric transport of air pollution. Atmos Chem Phys 15:11411-11432. doi: 10.5194/acp15-11411-2015

22. Japan Meteorological Agency (JMA) 2021. http://www.data.jma.go.jp/svd/vois/data/tokyo/volcano.html (in Japanese). Accessed 1 July 2021.

23. Kong L, Tang X, Zhu J, Wang Z, Fu JS, Wang X, Itahashi S, Yamaji K, Nagashima T, Lee H-J, Kim C-H, Lin C-Y, Chen L, Zhang M, Tao Z, Li J, Kajino M, Liao H, Wang Z, Sudo K, Wang Y, Pan Y, Tang G, Li M, Wu Q, Ge B, Carmichael GR (2020) Evaluation and uncertainty investigation of the $\mathrm{NO}_{2}, \mathrm{CO}$ and $\mathrm{NH}_{3}$ modeling over China under the framework of MICS-Asia III. Atmos Chem Phys 20:181-202. doi: 10.5194/acp-20-181-2020, 2020

24. Kreher K, Van Roozendael M, Hendrick F, Apituley A, Dimitropoulou E, Frieß U, Richter A, Wagner T, Lampel J, Abuhassan N, Ang L, Anguas M, Bais A, Benavent N, Bösch T, Bognar K, Borovski A, Bruchkouski I, Cede A, Chan KL, Donner S, Drosoglou T, Fayt C, Finkenzeller H, Garcia-Nieto D, Gielen C, Gómez-Martín L, Hao N, Henzing B, Herman JR, et al. (2020) Intercomparison of $\mathrm{NO}_{2}, \mathrm{O}_{4}, \mathrm{O}_{3}$ and $\mathrm{HCHO}$ slant column measurements by MAX-DOAS and zenith-sky UV-Visible spectrometers during CINDI-2. Atmos Meas Tech 13:2169-2208 doi: 10.5194/amt-13-2169-2020

25. Kurokawa J, Ohara T, Morikawa T, Hanayama S, Janssens-Maenhout G, Fukui T, Kawashima K, Akimoto H (2013) Emissions of air pollutants and greenhouse gases over Asian regions during 20002008: Regional Emission inventory in ASia (REAS) version 2. Atmos Chem Phys 13:11019-11058. doi: 10.5194/acp-13-11019-2013

26. Lin J-T. (2012) Satellite constraint for emissions of nitrogen oxides from anthropogenic, lightning and soil sources over East China on a high-resolution grid. Atmos Chem Phys 12:2881-2898. doi: 10.5194/acp-12-2881-2012

27. Liu F, van der A RJ, Eskes $\mathrm{H}$, Ding J, Mijling $B(2018)$ Evaluation of modeling $\mathrm{NO}_{2}$ concentrations driven by satellite-derived and bottom-up emission inventories using in situ measurements over China. Atmos Chem Phys 18:4171-4186. doi: 10.5194/acp-18-4171-2018

28. Mathur R, Xing J, Gilliam R, Sarwar G, Hogrefe C, Pleim J, Pouliot G, Roselle S, Spero TL, Wong DC, Young J (2017) Extending the Community Multiscale Air Quality (CMAQ) modeling system to hemispheric scales: overview of process considerations and initial applications. Atmos Chem Phys 17:12449-12474. doi: 10.5194/acp-17-12449-2017

29. Ministry of Environment (MOE) (2019) PM2.5 emission inventory. http://www.env.go.jp/air/osen/pm/info.html\#INVENTORY (in Japanese). Accessed 1 Jun 2021

30. Morrison H, Thompson G, Tatarskii V (2009) Impacts of cloud microphysics on the development of trailing stratiform precipitation in a simulated squall line: Comparison of one- and two-moment schemes. Mon Weather Rev 137:991-1007. doi: 10.1175/2008MWR2556.1 
31. National Centers for Environmental Prediction (NCEP)/National Center for Atmospheric Research (NCAR) (2021) Final (FNL) Operational Global Analysis Data. https://rda.ucar.edu/datasets/ds083.2/. Accessed 1 July 2021

32. Platt U, Stutz J (2008) Differential optical absorption spectroscopy: Principles and applications. Springer, Berlin/Heidelberg. doi: 10.1007/978-3-540-75776-4

33. Roscoe HK, Van Roozendael M, Fayt C, du Piesanie A, Abuhassan N, Adams C, Akrami M, Cede A, Chong J, Clémer K, Friess U, Gil Ojeda M, Goutail F, Graves R, Griesfeller A, Grossmann K, Hemerijckx G, Hendrick F, Herman J, Hermans C, Irie H, Johnston PV, Kanaya Y, Kreher K, Leigh R, Merlaud A, Mount GH, Navarro M, Oetjen H, Pazmino A, et al. (2010) Intercomparison of slant column measurements of $\mathrm{NO}_{2}$ and $\mathrm{O}_{4}$ by MAX-DOAS and zenith sky UV and visible spectrometers. Atmos Meas Tech 3:1629-1646. doi: 10.5194/amt-3-1629-2010

34. Skamarock WC, Klemp JB, Dudhia J, Gill DO, Barker DM, Duda MG, Huang X-Y, Wang W, Powers JG (2008) A description of the advanced research WRF version 3. NCAR Tech Note, NCAR/TN-475CSTR. doi: $10.5065 / 1 \mathrm{dfh}-6 \mathrm{p} 97$.

35. Seinfeld JH, Pandis SN (2016) Atmospheric Chemistry and Physics, From Air Pollution to Climate Change. Tthird ed. John Wiley, New York.

36. United States Environmental Protection Agency (US EPA). (2018). CMAQ (version 5.2.1). https://doi.org/10.5281/zenodo.1212601. Accessed 1 July 2021

37. Simon H, Bhave PV (2012) Simulating the degree of oxidation in atmospheric organic particles. Environ Sci Tech 46:331-339.

38. van der Werf GR, Randerson JT, Giglio L, van Leeuwen TT, Chen Y, Rogers BM, Mu M, van Marle MJE, Morton DC, Collatz GJ, Yokelson RJ, Kasibhatla PS (2017) Global fire emissions estimates during 1997-2016. Earth Syst Sci Data 9:697-720.

39. Wakamatsu S, Morikawa T, Ito A (2013) Air pollution trends in Japan between 1970 and 2012 and impact of urban air pollution countermeasures. Asian J Atmos Environ 7:177-190. doi: 10.5572/ajae.2013.7.4.177

40. Zheng B, Tong D, Li M, Liu F, Hong C, Geng G, Li H, Li X, Peng L, Qi J, Yan L, Zhang Y, Zhao H, Zheng Y, He K, Zhang Q (2018) Trends in China's anthropogenic emissions since 2010 as a consequence of clean air actions. Atmos Chem Phys 18:14095-14111. doi: 10.5194/acp-18-14095-2018

\section{Figures}



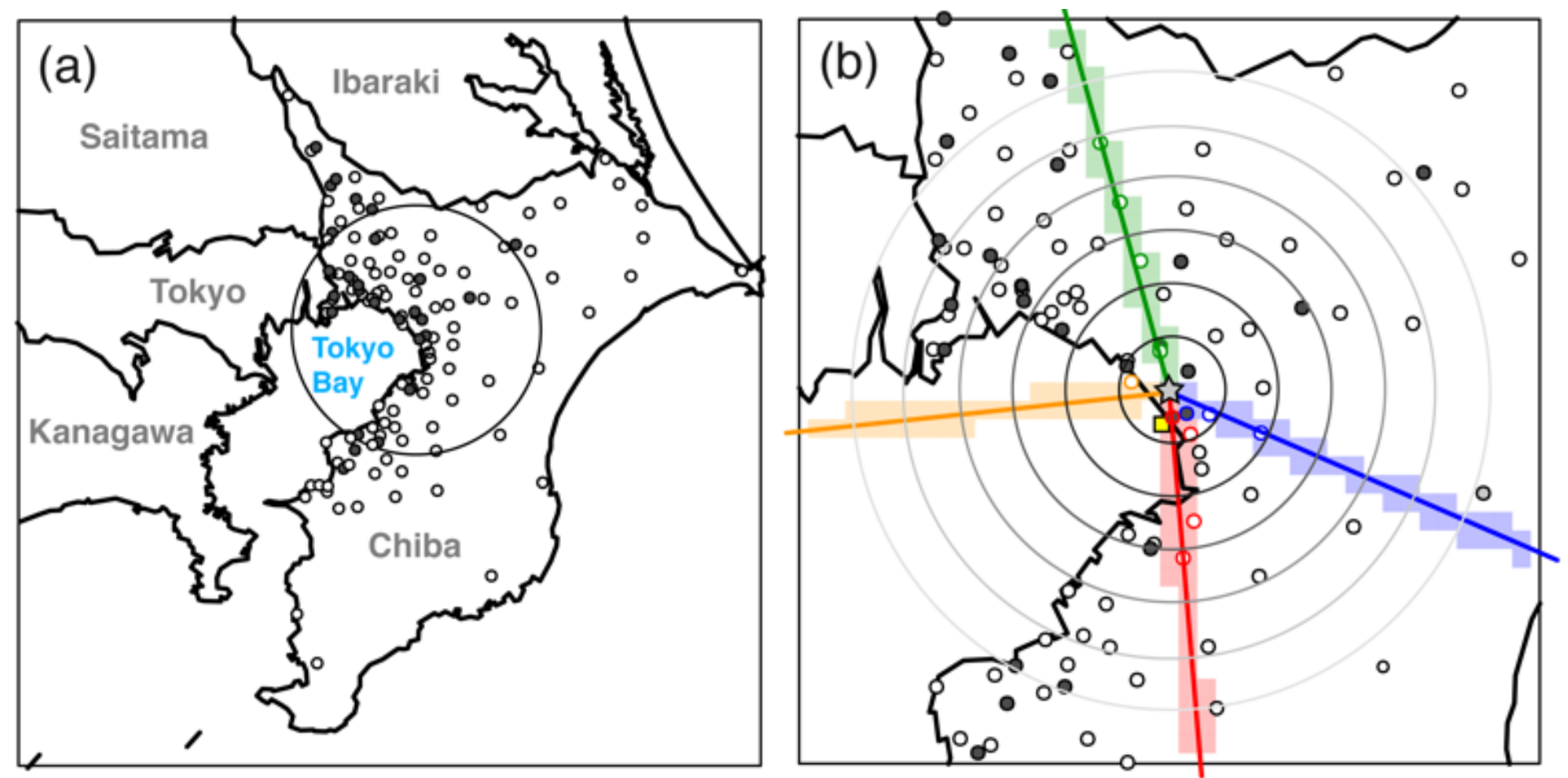

\begin{tabular}{|c|c|c|c|c|c|}
\hline \multirow{6}{*}{$\begin{array}{l}\text { AEROS } \\
\text { - APMSs } \\
\text { - RAPMSs }\end{array}$} & Chiba University & \multicolumn{4}{|c|}{ MAX-DOAS } \\
\hline & 记 & Directiol & & Distance from & Chiba University: \\
\hline & & 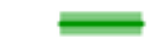 & North & - $4 \mathrm{~km}$ & - $16 \mathrm{~km}$ \\
\hline & AMeDAS & 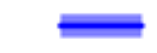 & East & - $8 \mathrm{~km}$ & $-20 \mathrm{~km}$ \\
\hline & 口 & $\underline{\underline{\underline{ }}}$ & West & - $12 \mathrm{~km}$ & $-24 \mathrm{~km}$ \\
\hline & & $\underline{\underline{ }}$ & South & & \\
\hline
\end{tabular}

Figure 1

Locations of ground-based observations by AEROS and 4AZ-MAX-DOAS. (a) Map of Kanto region, Japan and locations of ground-based observation by AEROS over Chiba prefecture. (b) Enlarged map around Chiba University, which is the center of $4 A Z-M A X-D O A S$. Circles are drawn at $4 \mathrm{~km}$ radius intervals from Chiba University up to $24 \mathrm{~km}$ (maximum horizontal distance observed by MAX-DOAS). AEROS observation sites are colored white (APMSs) and dark gray (RAPMSs).
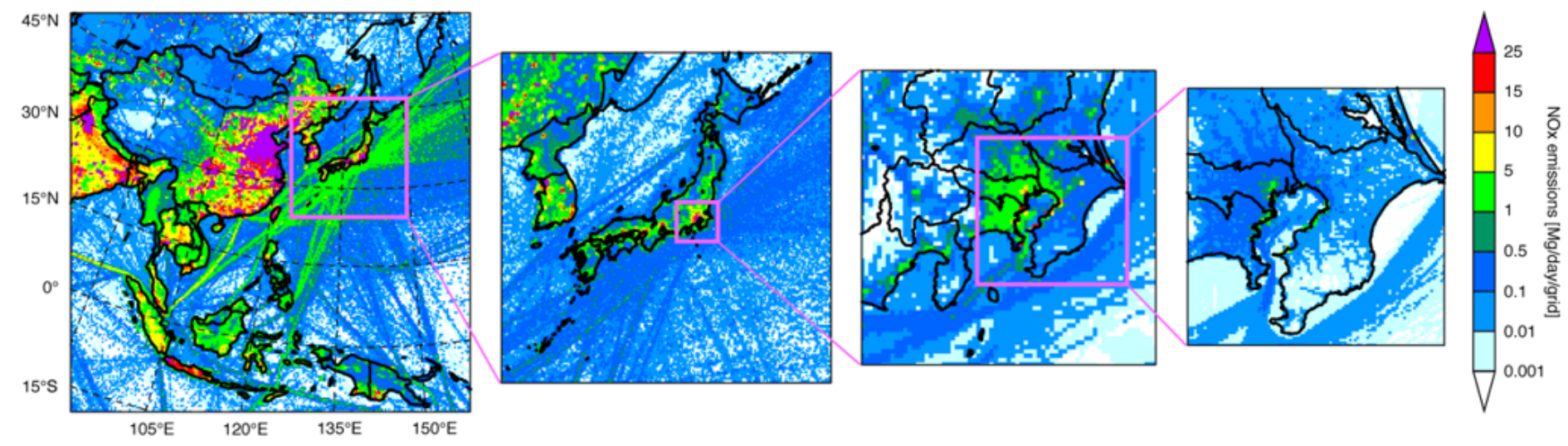

Figure 2 
NOx emission over quadruple nesting domains of air quality modeling system. The horizontal grid resolutions are $36,12,4$, and $1.3 \mathrm{~km}$.

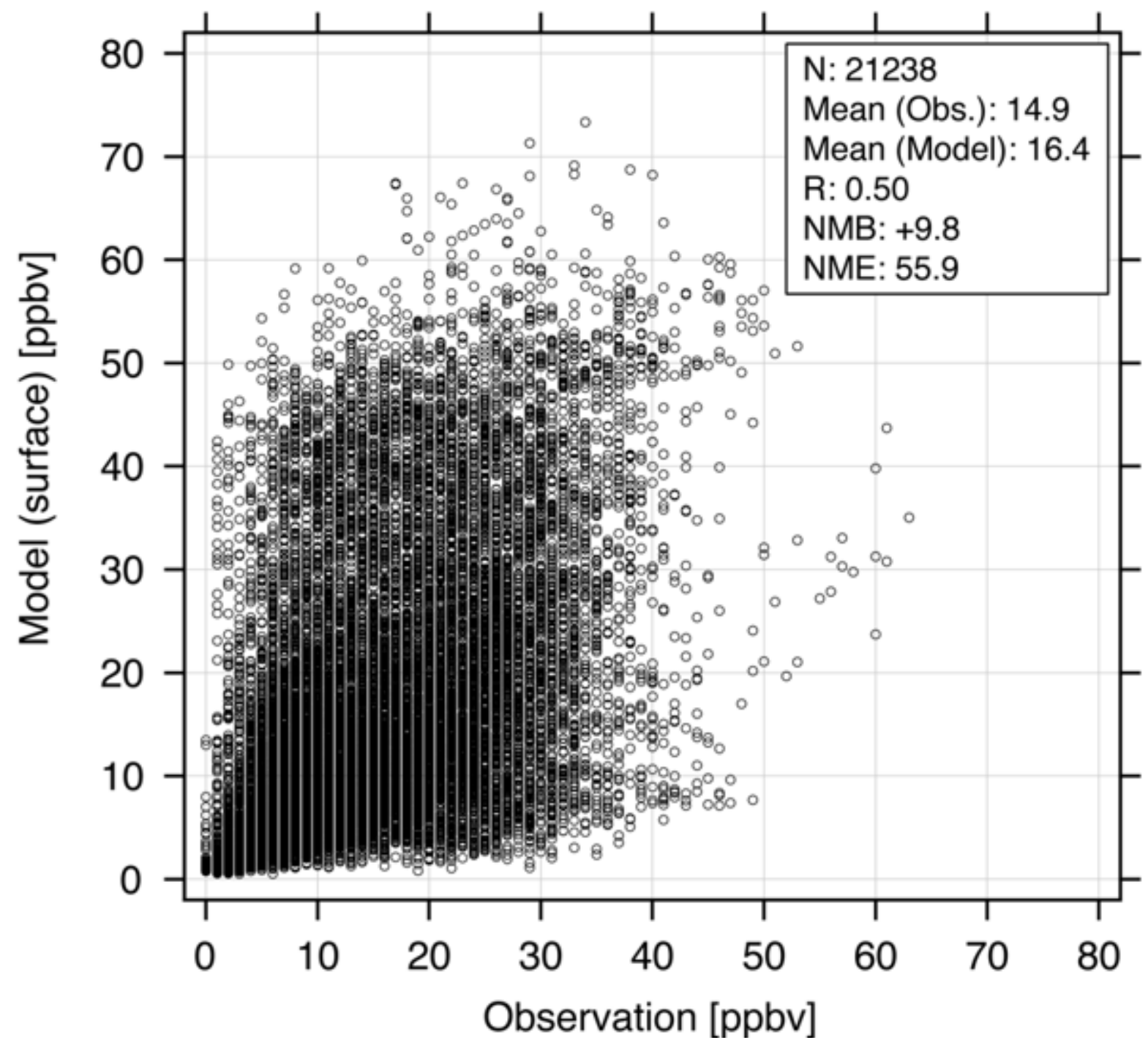

Figure 3

Scatter-plot of hourly surface level NO2 concentration during Chiba-Campaign 2015. Ground-based observation by AEROS and the model are shown. AEROS sites located within $24 \mathrm{~km}$ of Chiba University (see, Fig. 1) are used. 

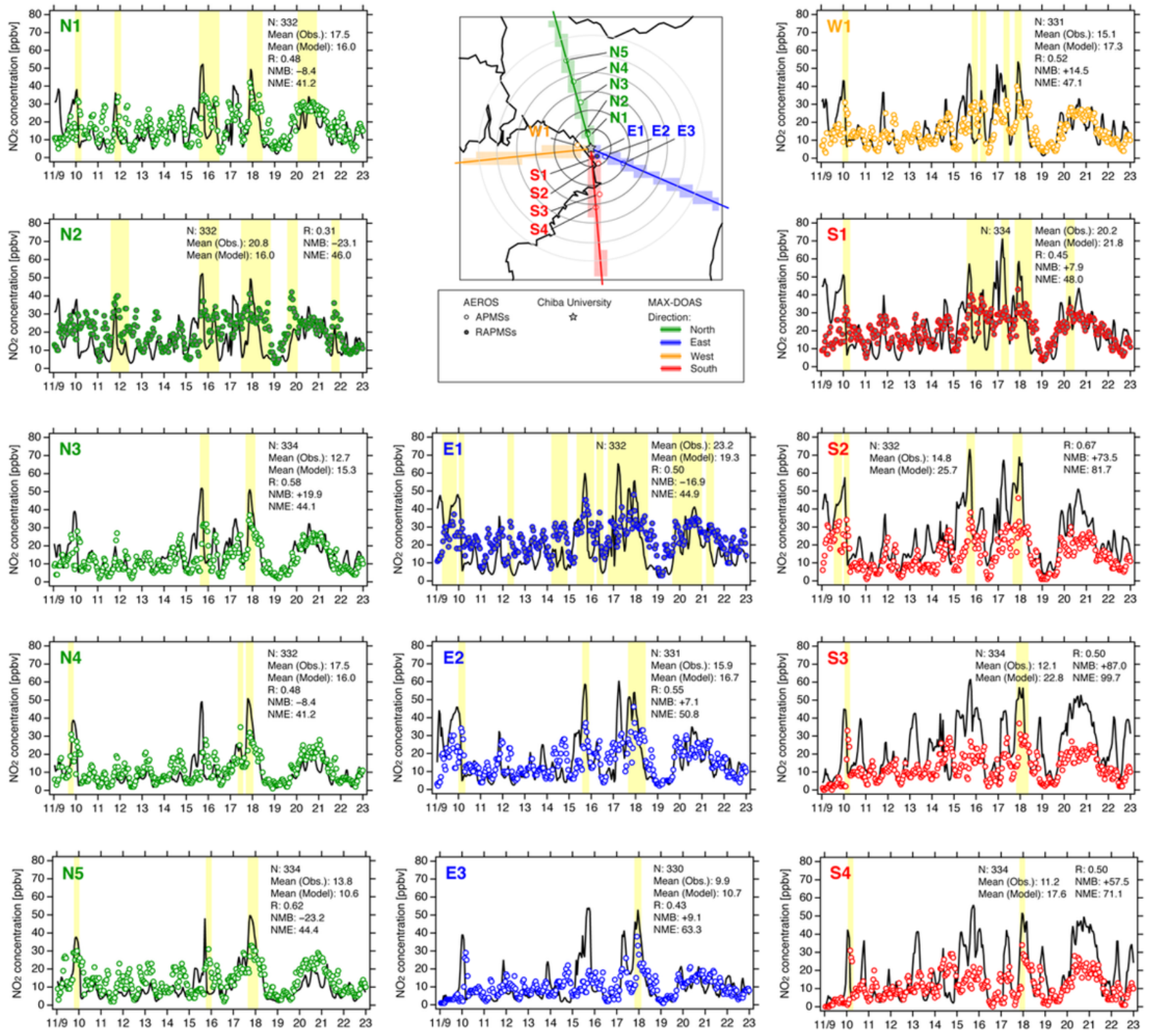

\section{Figure 4}

Temporal variation in hourly NO2 concentration at the surface level along 4AZ-MAX-DOAS measurement paths. Ground-based observation by AEROS and the model results are shown. AEROS sites are named in order of nearness to Chiba University in each direction. Statistical scores are shown at the top-right of each panel. Yellow highlighting denotes high NO2 concentration defined as greater than $30 \mathrm{ppbv}$. See also Fig. 1. 

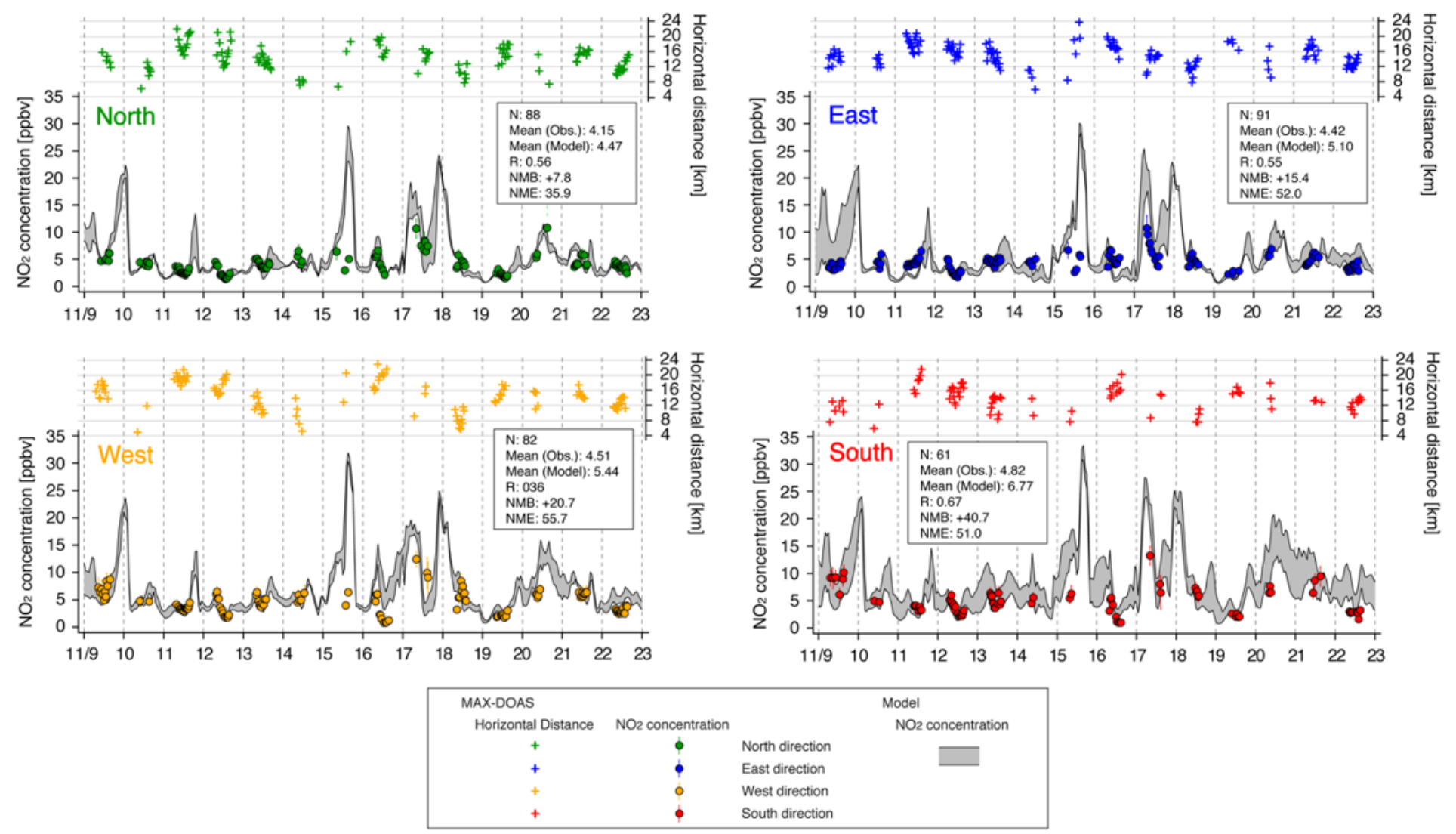

Figure 5

Temporal variation of NO2 concentration by MAX-DOAS and model averaged over 0-1 km (each direction). The MAX-DOAS measured horizontal distance is also plotted. The range of model results showed simulated NO2 concentration within 4-24 km from Chiba University at each direction. Statistical scores are shown in the inset, and 1-hour averaged MAX-DOAS observation and corresponded horizontal distance to observation were used for this analysis. 
Surface
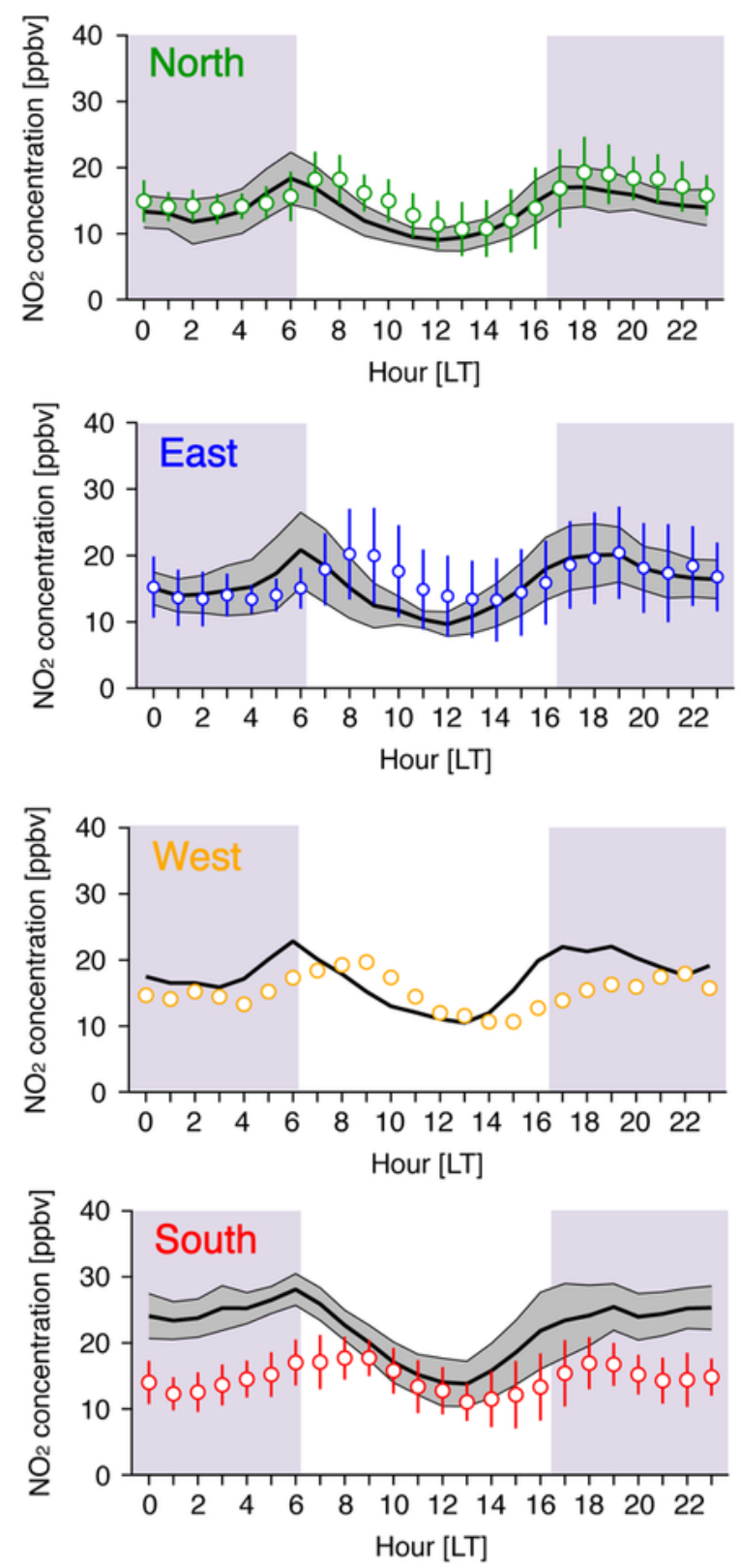

Aloft (0-1 km)
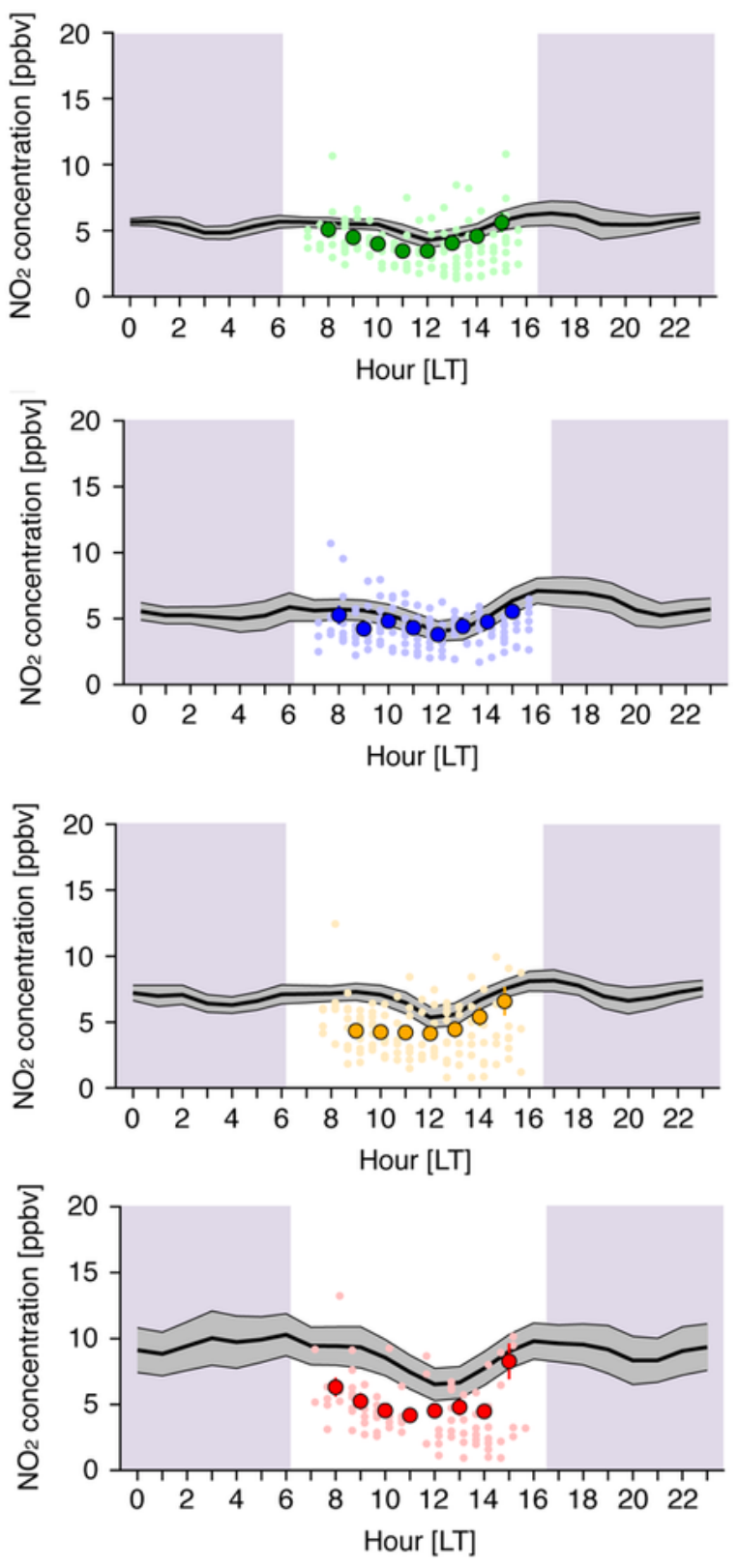

$\begin{array}{lccl} & \text { AEROS } & \text { MAX-DOAS } & \text { Model } \\ \text { North direction } & \phi & \phi & \\ \text { East direction } & \phi & \phi & = \\ \text { West direction } & 0 & 0 & \\ \text { South direction } & \phi & \phi & \end{array}$

\section{Figure 6}

Diurnal variation of NO2 concentration at (left) surface and (right) aloft. Surface data are taken from AEROS sites located along 4AZ-MAX-DOAS directions and model results at surface level. Aloft data is taken from MAX-DOAS with light colors for all data and thick colors for 1 hour averaged data, and model results averaged over 0-1 km. Shading with dark blue indicates nighttime. 
(a)

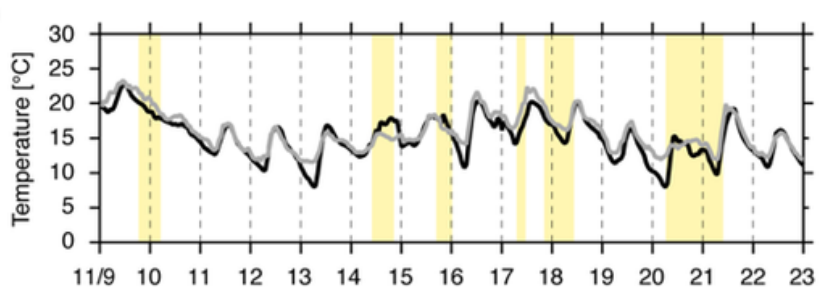

(c)

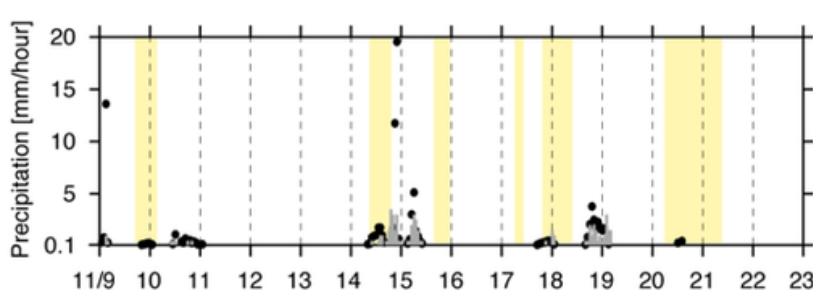

(e)

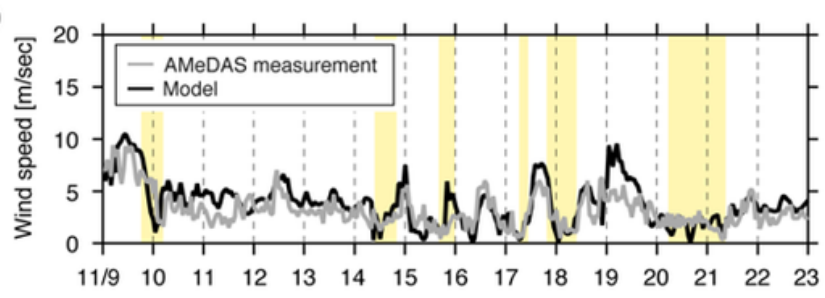

(d)

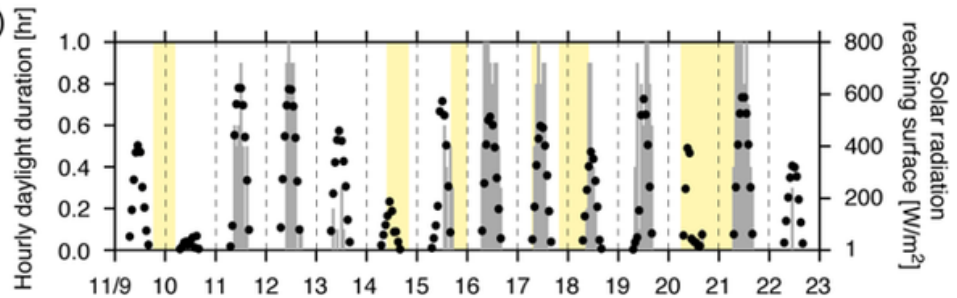

(d)

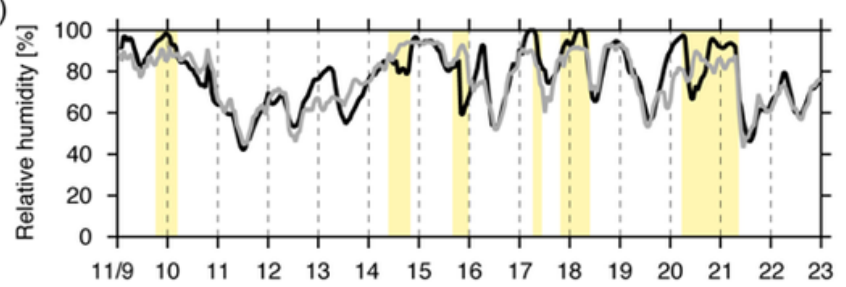

(f)

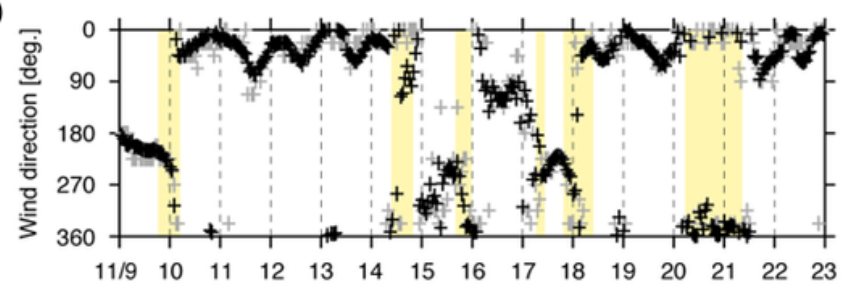

\section{Figure 7}

Meteorological field measured at AMeDAS Chiba (gray lines) and model results (black lines). The results shown are for (b) wind speed, (c) wind direction, (d) temperature, (e) precipitation, and (f) relative humidity. In (d), observation of the duration time of sunlight per day is also shown. 


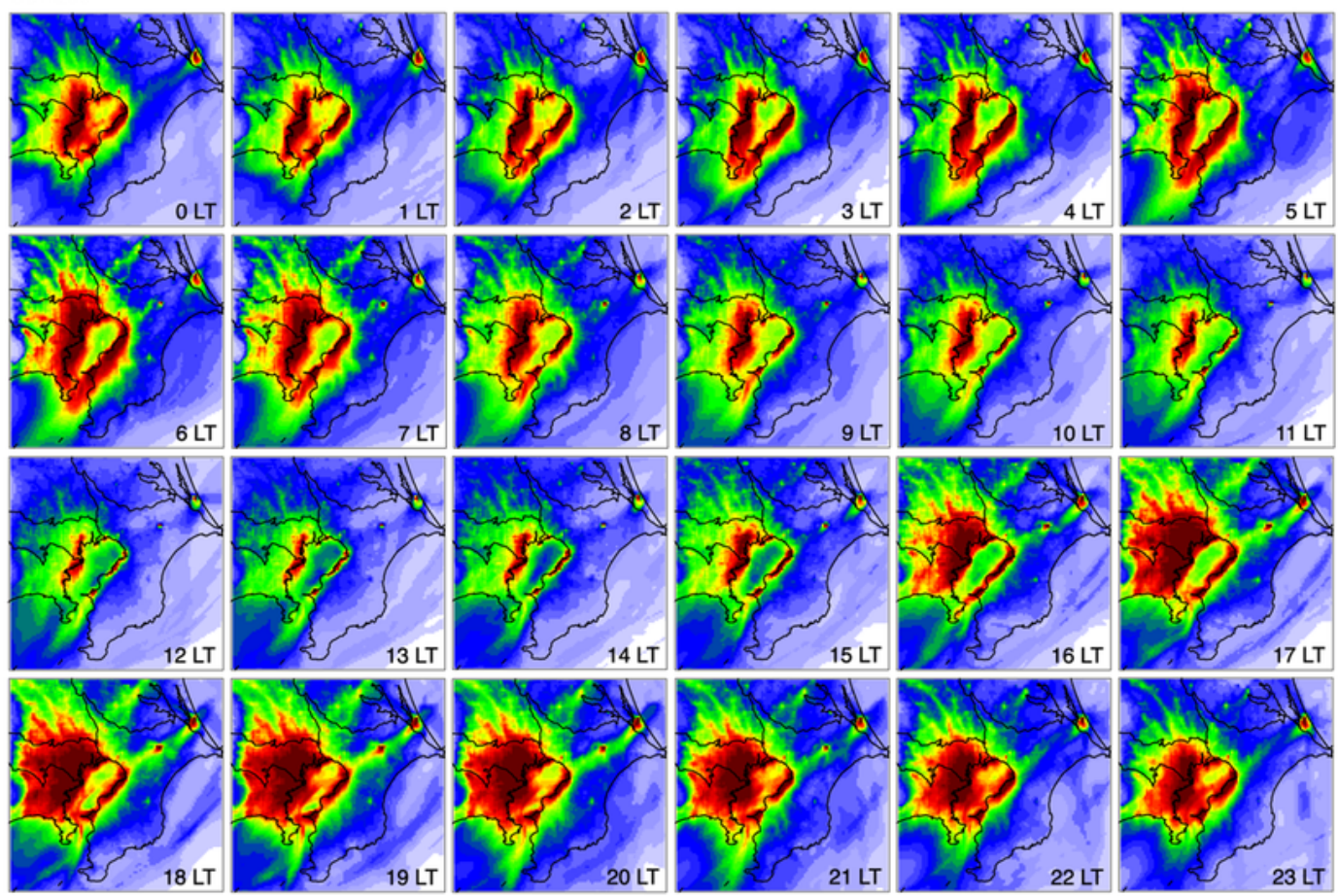

Aloft (0-1 km)

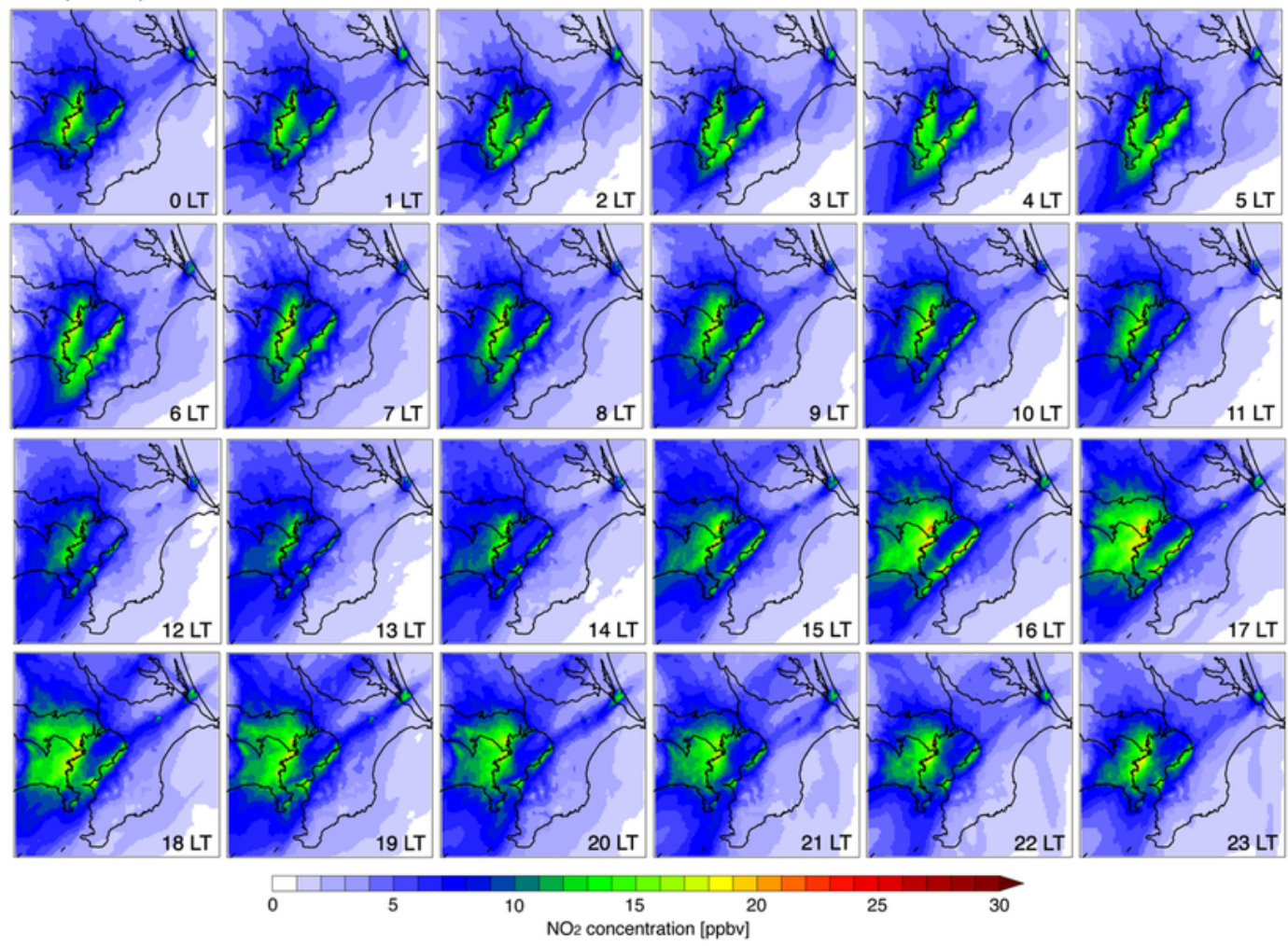

Figure 8

Spatial distribution of modeled hourly NO2 concentration at surface and aloft (averaged over 0-1 km). Results are averages over the Chiba-Campaign 2015. 

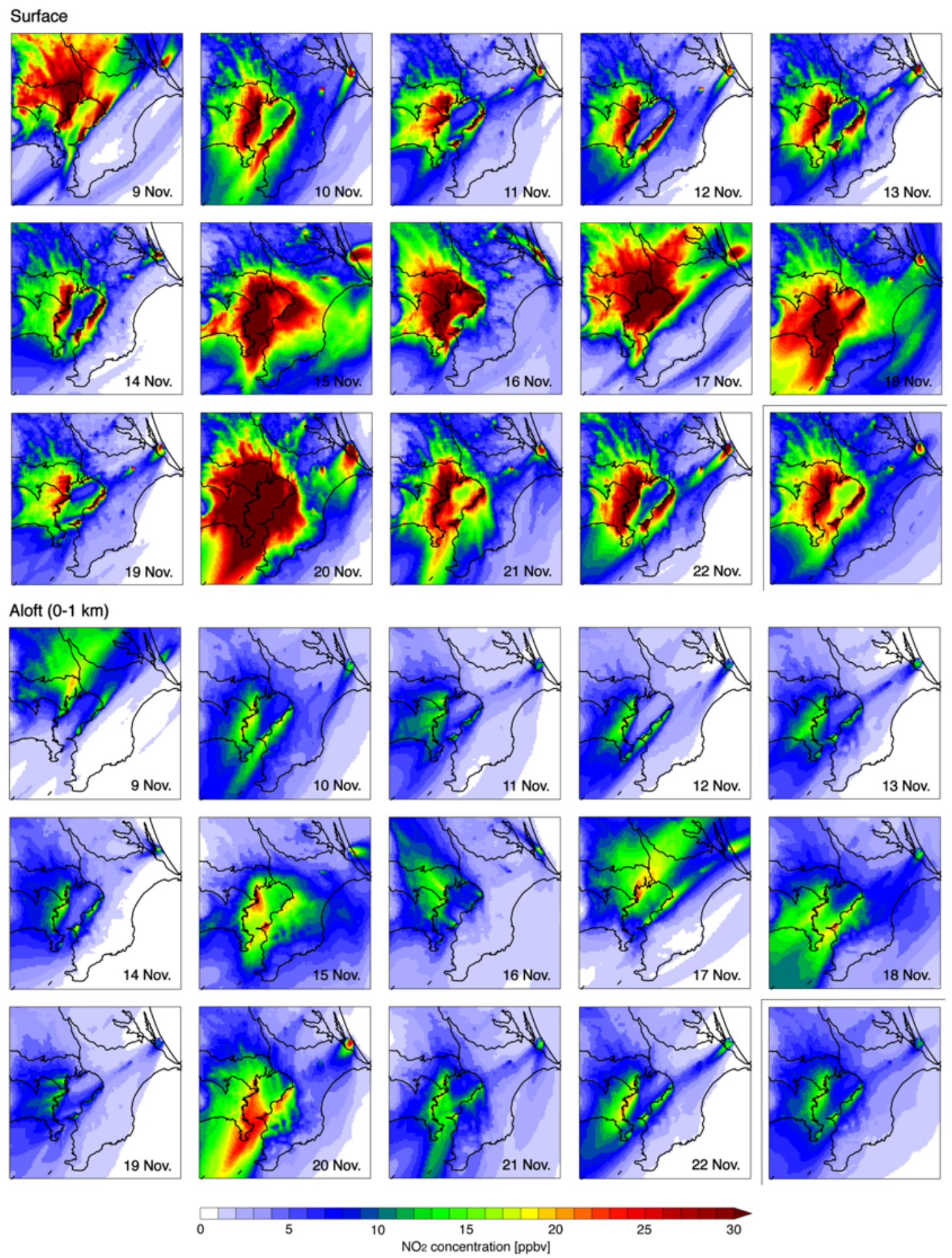

\section{Figure 9}

Spatial distribution of modeled daily NO2 concentration at surface and aloft (averaged over 0-1 km). The right-bottom panel shows the period average over the Chiba-Campaign 2015. 


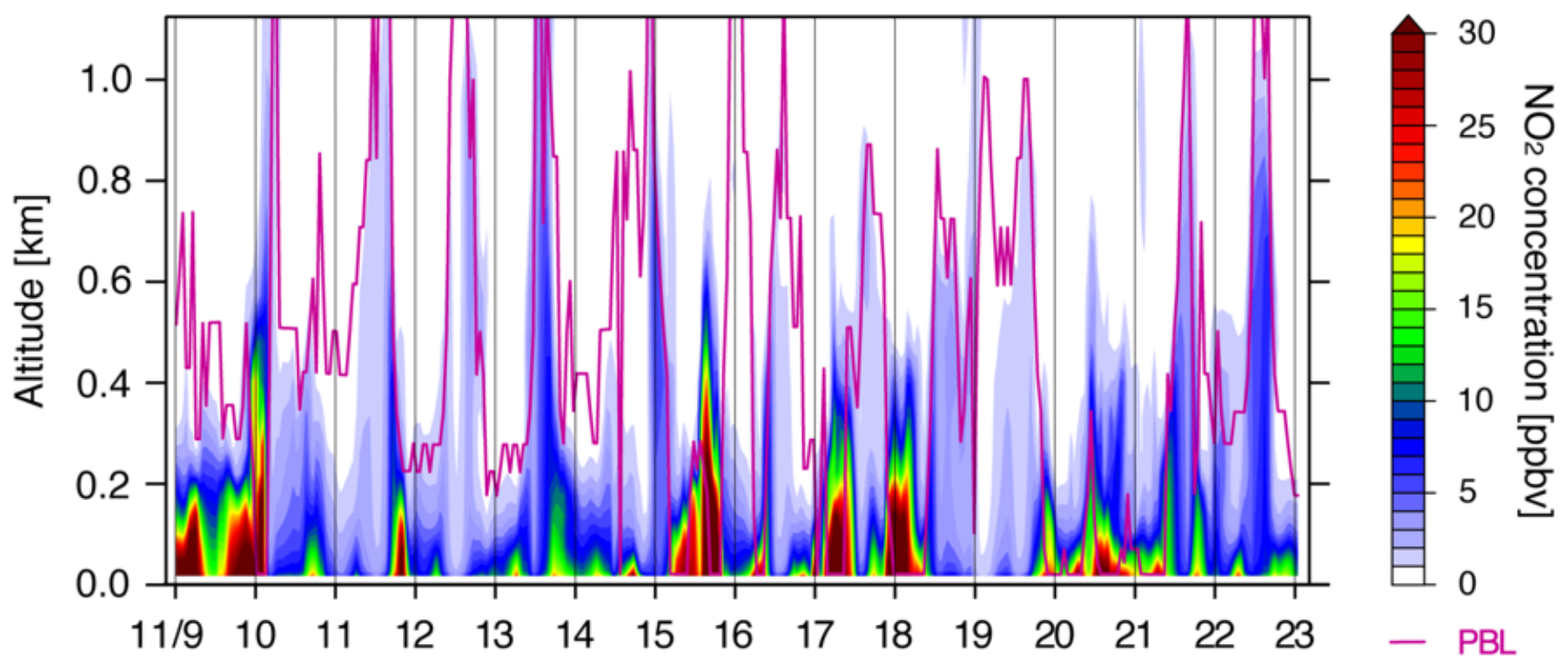

Figure 10

Curtain plot of modeled NO2 concentration during Chiba-Campaign 2015. The thick pink line indicates modeled planetary boundary layer $(\mathrm{PBL})$ height.

\section{Supplementary Files}

This is a list of supplementary files associated with this preprint. Click to download.

- GA.png 